\title{
Subcellular Profiling Reveals Distinct and Developmentally Regulated Repertoire of Growth Cone mRNAs
}

\author{
Krishna H. Zivraj, ${ }^{1 \star}$ Yi Chun Loraine Tung, ${ }^{2 \star}$ Michael Piper, ${ }^{3}$ Laura Gumy, ${ }^{4}$ James W. Fawcett, ${ }^{4}$ Giles S. H. Yeo, ${ }^{2}$ \\ and Christine E. Holt ${ }^{1}$ \\ ${ }^{1}$ Department of Physiology, Development, and Neuroscience, University of Cambridge, Cambridge CB2 3DY, United Kingdom, ${ }^{2}$ Institute of Metabolic \\ Science, University of Cambridge, Addenbrooke's Hospital, Cambridge CB2 0QQ, United Kingdom, ${ }^{3}$ Queensland Brain Institute, The University of \\ Queensland, St. Lucia, Queensland 4072 Australia, and ${ }^{4}$ Cambridge Centre for Brain Repair, University of Cambridge, Cambridge CB2 0PY, United \\ Kingdom
}

Cue-directed axon guidance depends partly on local translation in growth cones. Many mRNA transcripts are known to reside in developing axons, yet little is known about their subcellular distribution or, specifically, which transcripts are in growth cones. Here laser capture microdissection (LCM) was used to isolate the growth cones of retinal ganglion cell (RGC) axons of two vertebrate species, mouse and Xenopus, coupled with unbiased genomewide microarray profiling. An unexpectedly large pool of mRNAs defined predominant pathways in protein synthesis, oxidative phosphorylation, cancer, neurological disease, and signaling. Comparative profiling of "young" (pathfinding) versus "old" (target-arriving) Xenopus growth cones revealed that the number and complexity of transcripts increases dramatically with age. Many presynaptic protein mRNAs are present exclusively in old growth cones, suggesting that functionally related sets of mRNAs are targeted to growth cones in a developmentally regulated way. Remarkably, a subset of mRNAs was significantly enriched in the growth cone compared with the axon compartment, indicating that mechanisms exist to localize mRNAs selectively to the growth cone. Furthermore, some receptor transcripts (e.g., EphB4), present exclusively in old growth cones, were equally abundant in young and old cell bodies, indicating that RNA trafficking from the soma is developmentally regulated. Our findings show that the mRNA repertoire in growth cones is regulated dynamically with age and suggest that mRNA localization is tailored to match the functional demands of the growing axon tip as it transforms into the presynaptic terminal.

\section{Introduction}

Many polarized and migrating cell types show subcellular mRNA localization (Martin and Ephrussi, 2009). mRNA localization confers precise spatial control over where new proteins are synthesized and contributes to the specialization of axonal and dendritic compartments in neurons (Job and Eberwine, 2001; Bramham and Wells, 2007; Lin and Holt, 2008). As neurons differentiate, they send out axons tipped with growth cones that show a remarkably autonomous ability to respond directionally to extrinsic signals. This behavior is controlled partly by the polarized transport and translation of specific mRNAs that regulate the cytoskeleton: attractive cues, such as netrin-1 and BDNF,

Received April 8, 2010; revised July 29, 2010; accepted Aug. 21, 2010.

This work was funded by Wellcome Trust Programme Grant 085314/Z/08/Z (C.E.H.), Medical Research Council Project Grant G0501592 (J.W.F., C.E.H.), the United Kingdom Medical Research Council Centre for Obesity and Related Metabolic Disorders (G.S.H.Y., Y.C.L.T.), and European Union FP7 Grant HEALTH-2009-241592 EurOCHIP. The array data described in this manuscript has been deposited in GE0, accession number GSE25166. We thank Sarah Piper for invaluable help with initiating the studies, Bill Harris, Hosung Jung, Catherine $0^{\prime} H a r e$, and Caren Norden for valuable comments on this manuscript, Andrew Lin for thymosin riboprobes, Ashish Pungaliya, Thomas Dyl, and Adrian McNabb for technical assistance, and Joyce Lam for help with mouse retinal cultures.

*K.H.Z. and Y.C.L.T. contributed equally to this work.

Correspondence should be addressed to either of the following: Christine Holt, Department of Physiology, Development, and Neuroscience, University of Cambridge, Downing Street, Cambridge CB2 3DY, UK, E-mail: ceh@mole.bio.cam.ac.uk; or Giles Yeo, University of Cambridge Metabolic Research Labs, Level 4, Institute of Metabolic Science, Box 289, Addenbrooke's Hospital, Cambridge CB2 00Q, UK, E-mail: gshy2@cam.ac.uk.

DOI:10.1523/JNEUROSCI.1800-10.2010

Copyright $\odot 2010$ the authors $\quad$ 0270-6474/10/3015464-15\$15.00/0 regulate the localized translation of mRNAs, such as $\beta$-actin, to build up the growth cone cytoskeleton (Leung et al., 2006; Yao et al., 2006), whereas repellent cues elicit de novo synthesis of proteins, such as RhoA and cofilin for cytoskeletal disassembly (Wu et al., 2005; Piper et al., 2006). Growth cone adaptation, an important gradient sensing mechanism, also involves local protein synthesis (Ming et al., 2002; Piper et al., 2005). Growing axons contain a diverse population of mRNAs (Koenig and Giuditta, 1999; Taylor et al., 2009; Andreassi et al., 2010), and the composition can be altered rapidly by factors, such as neurotrophins (Willis et al., 2005, 2007), including an increase of $\beta$-actin transcripts in growth cones (Bassell et al., 1998). However, it is not known whether the transcriptome of the growth cone is a faithful copy of that of the axon or whether this subcellular compartment has a distinct pool of mRNAs.

Growth cone responsiveness to guidance cues changes with time. Retinal ganglion cells (RGCs) and spinal cord commissural interneurons are initially attracted to netrin- 1 but are repelled by it just hours later (Shirasaki et al., 1996; Stein et al., 2001; Shewan et al., 2002). Commissural neurons change their responsiveness to netrin-1 attributable to netrin-1 exposure itself, but in RGCs, this change is cue independent because it is preserved in naive axons grown in vitro without pathway experience. Furthermore, RGC axons older than $10 \mathrm{~h}$ gain responsiveness to cues, such as Sema3A, Slit2, and LPA (Campbell et al., 2001; Piper et al., 2006), that they do not respond to initially. These developmental changes involve receptor regulation, but the mechanisms are poorly understood. 
One possibility is that the developmental changes are driven by RNA localization. By changing mRNA content over time, growth cones could alter their local proteome. Here, we used laser capture microdissection (LCM) of nonstimulated RGC growth cones coupled with an unbiased genomewide microarray technology to address three key questions. What is the full repertoire of retinal growth cone mRNAs? Does mRNA composition in growth cones change dynamically over a $24 \mathrm{~h}$ period? Do mRNA pools differ between growth cones and axons? We found that RGC growth cones in mouse and Xenopus have a surprisingly large number of mRNAs belonging to similar functional categories. Some are specifically targeted to the growth cone itself. Moreover, the growth cone transcriptome becomes increasingly complex with time as it advances along the retinotectal pathway.

\section{Materials and Methods}

Retinal cell culture. Xenopus laevis embryos were obtained by in vitro fertilization and raised in $0.1 \times$ Barth's saline between 14 and $20^{\circ} \mathrm{C}$. Embryos were staged according to the tables of Nieuwkoop and Faber (1967). Whole-eye primordia from stage 24 and 32 embryos were cultured on polyethylene terephthalate (PET) membrane slides (Leica Microsystems) coated with poly-L-lysine ( $10 \mu \mathrm{g} / \mathrm{ml}$; Sigma) and laminin (10 $\mu \mathrm{g} / \mathrm{ml}$; Sigma) for 17 and $24 \mathrm{~h}$, respectively, at $20^{\circ} \mathrm{C}$. For fluorescent in situ hybridization (FISH), stage 32 eyes were cultured on coverslips coated with poly-L-lysine and laminin for $24 \mathrm{~h}$ unless otherwise stated. For mouse retinal explants, retina from embryonic day 15 (E15) mouse embryos were cultured for $24 \mathrm{~h}$ as reported previously (Cheung et al., 2005).

Laser-capture microdissection of RGC growth cones, axon segments, and cell bodies. Retinal cultures were stained with fluorescent lipophilic dye FM1-43 [N-(3-triethylammoniumpropyl)-4-(4-(dibutylamino)styryl) pyridinium dibromide] (Invitrogen) (Brumback et al., 2004) for $20 \mathrm{~min}$ to aid visualization and fixed with freshly prepared $4 \%$ paraformaldehyde (PFA) in 4\% sucrose in PBS for 10 min. Cultures were dehydrated through an ethanol series and air dried. Dye-labeled growth cones/axons were selected for capture at $40 \times$ magnification, and samples were dissected and collected by microscopic laser-based dissection using the Leica laser microdissection system LMD6000 (Leica Microsystems). For growth cone laser capture, circles of $15 \mu \mathrm{m}$ diameter were drawn around individual growth cones at $40 \times$. RGC cell bodies from stage 32 and $40 X$. laevis retinal cryosections were isolated as described previously (Lin et al., 2009). Briefly, stage 32 ("young" corresponding to stage $24+17$ h cultures) and stage 40 ("old" corresponding to stage $32+24$ h cultures) embryos were fixed for 15 min with $4 \%$ PFA in PBS, and $14 \mu \mathrm{m}$ horizontal retinal cryosections were collected on PET membrane slides. The sections were stained with nuclear labeling dye cresyl-violet blue for 1 min and dehydrated through an ethanol series. The RGC layer was isolated by laser capture at $20 \times$ magnification.

RNA extraction and amplification. RNA was extracted immediately with RNAqueous Microkit (Ambion). Typically, $\sim 1000$ growth cones, 250 axon segments, and 30 cell bodies were collected for each experimental round. The yield of total RNA from 1000 growth cones was undetectable with current available quantification methods but was estimated to be $\sim 3$ pg, based on the known power of the linear amplification. Extracted RNA was linearly amplified using the two-cycle TargetAmp kit (Epicenter), and a third round incorporating a biotin tag into the resulting antisense RNA (aRNA) was done using the GeneChip IVT labeling kit (Affymetrix). The final yield of aRNA was $\geq 16 \mu \mathrm{g}$ of aRNA. This type of amplification introduces a 3' bias (Phillips and Eberwine, 1996), and, hence, RNA quality was assessed both after two- and three-cycle amplification using an Agilent 2100 Bioanalyzer (Agilent Technologies). aRNA from growth cones and axons with a broad range of fragment sizes (503000 bp) and on average $>200$ bp in length (supplemental Fig. S1, available at www.jneurosci.org as supplemental material) were used for microarray analysis, thus ensuring a relatively good linear amplification (Patel et al., 2005) but minimizing variability attributable to different aRNA size.
Microarray hybridization and data analysis. Fifteen micrograms of biotin-labeled aRNA was hybridized following the protocol of the manufacturer to Affymetrix arrays (X. laevis genome arrays or Murine 4302.0 whole-genome arrays) containing oligonucleotide probe sets complimentary to $3^{\prime}$ ends of the mRNA transcripts. Each independent experiment consisted of at least four biological replicates hybridized onto four arrays. Raw image data were converted to CEL files using Affymetrix GeneChip Operating Software. All downstream analysis of microarray data was performed using GeneSpring GX 7.3 (Agilent). Analysis of probe signal intensity levels across arrays was done using robust multiple averaging (RMA) and its variant guanine cytosine (GC)-RMA (Cope et al., 2006). The RMA and GC-RMA calculated expression values were normalized to the 50th percentile of the chip. Genes were considered "present" with an intensity $>30$ using RMA or $>10$ using GC-RMA. Functional categories of all $X$. laevis genes were manually curated using National Center for Biotechnology Information (NCBI) Gene tool.

Functional analyses were performed using Ingenuity Pathway Analysis (IPA) (Ingenuity Systems Inc.). The "functions" analysis identified the biological functions and diseases that were most significant to the dataset. A right-tailed Fisher's exact test was used to calculate a $p$ value determining the probability that each biological function and disease assigned to that dataset is attributable to chance alone.

The "pathways" analysis identified canonical pathways from the IPA library that were most significant to the dataset. The significance of the association between the dataset and the pathway was measured in two ways: (1) a ratio of the number of molecules from the dataset that map to the pathway divided by the total number of molecules that map to the canonical pathway is displayed; (2) Fisher's exact test was used to calculate a $p$ value determining the probability that the association between the genes in the dataset and the pathway is explained by chance alone.

To determine gene enrichment in the different subcellular compartments (growth cone vs axon), signal intensities of genes considered to be present in the growth cone compartment were compared with their corresponding signal intensity in the axonal compartment.

Real-time PCR. We validated our array data with quantitative reverse transcription-PCR (Q-PCR) analysis on 40 genes using independent biological replicates. Q-PCR was performed using SYBRGreen Expression assays on an ABI 7900HT (Applied Biosystems). Primer pairs designed against $X$. laevis sequence were tested for the PCR amplification efficiency (supplemental List S2 A, available at www.jneurosci.org as supplemental material) on whole-eye total RNA, and standard curves were constructed from eight twofold serial dilutions ranging from 6 to $800 \mathrm{ng}$. Only primers with amplification efficiency above $80 \%$ were used for additional analysis on growth cones. For each primer pair, dissociation curve analysis was also performed immediately after the amplification to ensure presence of a single amplicon. mRNA isolated from $\sim 1000$ growth cones was amplified as before for microarrays but without biotin label in the final round of amplification. First-strand cDNA was synthesized from 500 ng of the amplified RNA using SuperScript III reverse transcriptase primed by random primer. Real-time PCR was performed using SYBRGreen PCR master mix with $900 \mathrm{~nm}$ of the tested primers and reactions run in a total volume of $12 \mu \mathrm{l}$. The reaction was initiated by enzyme activation at $50^{\circ} \mathrm{C}$ for $2 \mathrm{~min}$ and $95^{\circ} \mathrm{C}$ for $10 \mathrm{~min}$, followed by 40 cycles of $15 \mathrm{~s}$ at $95^{\circ} \mathrm{C}, 1 \mathrm{~min}$ at $60^{\circ} \mathrm{C}$. Only those transcripts showing a cycle threshold (CT) value of $<38$ cycles with good amplification plot were considered as present. The use of dilution series samples (six twofold serial dilutions from 12.5 to $400 \mathrm{ng}$ input) demonstrate a dosedependent relationship between RNA input and PCR amplification. This allowed for greater assurance that all amplifications measured were specific, consistent, and within the appropriate linear range. For EphB4 Q-PCR analysis $(n=4)$, aRNA from isolated cell bodies was used to compare expression in old versus young RGC cell bodies (see Fig. $5 H$ ). "No template" control wells were used for each transcript.

Fluorescence in situ hybridization. RGC cultures were fixed for $15 \mathrm{~min}$ at room temperature in freshly prepared $4 \%$ PFA and $4 \%$ sucrose in PBS and permeabilized for $5 \mathrm{~min}$ in $0.3 \%$ Triton X-100 (Sigma) in PBS. IMAGE clones corresponding to the selected genes were used to transcribe riboprobes (supplemental List S2 B, available at www.jneurosci. org as supplemental material). Riboprobe preparation and in situ 
hybridization was performed following the procedure described previously (Blichenberg et al., 1999) with the following modifications. After probe hybridization, the digoxygenin (DIG)-labeled probe was detected immunocytochemically by incubation with mouse monoclonal cyanine-3 (Cy3)-coupled digoxygenin antibody (Roche Diagnostics) in blocking buffer overnight at $4^{\circ} \mathrm{C}$. Cy3-coupled goat anti-mouse antibody (Jackson ImmunoResearch) was used to visualize the DIG-labeled RNA. Samples were mounted in Permafluor (Beckman Coulter).

Image acquisition, quantitative immunofluorescence, and statistical analysis. For quantification of the fluorescence in situ signal (FISH), growth cones free of adjacent cells were selected at random with phase optics at $100 \times$ on a Nikon Eclipse 80i microscope, and a Hamamatsu ORCA-ER camera was used to capture a phase image immediately followed by a fluorescence image. Care was taken to avoid pixel saturation and to use the same gain and exposure settings for fluorescence image capture for each experiment. For quantification of fluorescence intensity, the growth cone outline was traced with a drawing pad on the phase image and superimposed on the fluorescent image. Openlab software (Improvision) was used to calculate fluorescent intensity within the growth cone, giving a measurement of pixel intensity per unit area. The background fluorescence in the adjacent area void of biological material was similarly calculated to record the background pixel intensity per unit area. This reading was then subtracted from the growth cone reading, resulting in the backgroundcorrected intensity. The fluorescent intensities of at least 20 growth cones per experiment were collected. The data represent three independent experiments for each mRNA transcript, and the data were normalized against the corresponding sense controls. For mRNA granule density measurement in growth cone and axonal compartments, a set area of 1000 pixels was selected in (1) the central domain of the growth cone and (2) the axonal segment at least $50 \mu \mathrm{m}$ away from the growth cone with Openlab software. The number of puncta present within the selected area was counted for each compartment. The data represent two independent experiments for each mRNA transcript, and each experiment comprised 20 growth cones. Statistical analyses were done with InStat3 (GraphPad Software) using two-tailed Mann-Whitney $U$ test for the FISH (see Fig. 4) and for mean granule density (MGD) measurement and KruskalWallis test (see Fig. $5 G$ ).

\section{Results}

\section{Isolation and microarray analysis of growth cone mRNAs}

To characterize the full repertoire of mRNAs that reside in retinal growth cones, we used LCM combined with microarray analysis. RGC axons from stage 32 Xenopus eyes were cultured for $24 \mathrm{~h}$, a duration that corresponds approximately to the arrival of axons in the optic tectum in vivo (Holt, 1984; Dingwell et al., 2000). For each experiment, $\sim 1000$ growth cones were laser captured individually, avoiding contamination from other cellular sources (Fig. 1). Total RNA was extracted, amplified, and hybridized onto Affymetrix $X$. laevis genome arrays that contain $\sim 14,400$ transcripts providing comprehensive coverage of the Xenopus genome. Two different algorithms, RMA (Cope et al., 2006) and GC-RMA (Wu et al., 2004), were used to analyze the data obtained from four biological replicates (see Materials and Methods). In contrast to standard microarray experiments performed with nanogram to microgram amounts of starting material, our growth cone aRNA samples were derived from extremely minute quantities of total RNA after three rounds of linear amplification $(\sim 3$ pg of total RNA from 1000 growth cones; see Materials and Methods). RMA
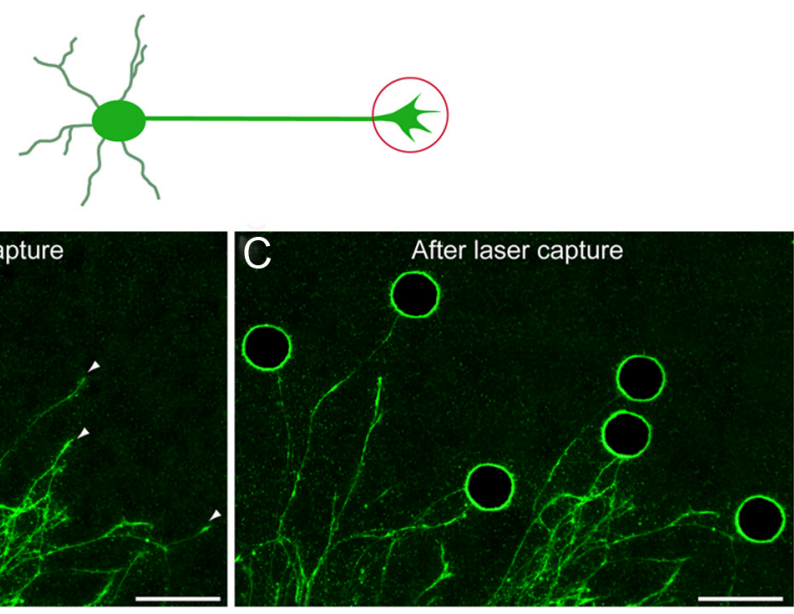

After laser capture

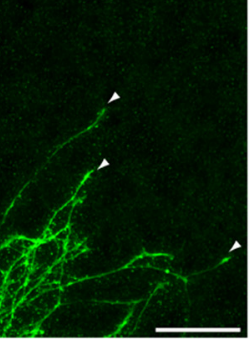

sentation of an RGC showing the growth cone selected for LCM at $10 \times$ magnification. Before $(\boldsymbol{B})$ and after $(\boldsymbol{C})$ LCM micrographs of FM1-43 labeled Xenopus stage 32 retinal growth cones cultured on PET membrane slides. Scale bar, $150 \mu \mathrm{m}$.

reduces the variance of low abundance transcripts to better distinguish differentially expressed transcripts from those that are unchanging, whereas GC-RMA uses intensity summaries generated across sets of probes to estimate nonspecific binding, thereby improving overall detection sensitivity. Thus, to get full coverage of the growth cone transcriptome including low expressing genes, we combined the lists of genes detected using both algorithms. The RMA analysis identified 399 genes as present, and the GC-RMA analysis identified 768 genes (supplemental Fig. S3A, available at www.jneurosci.org as supplemental material). There was an overlap of 209 genes between the two types of analyses and a total of 958 different transcripts when both sets of analysis were combined (supplemental Fig. S3A, available at www.jneurosci. org as supplemental material). These 958 transcripts represented $\sim 6 \%$ of the total number of transcripts on the array. Whereas RMA analysis identified the relatively high abundance transcripts (probe intensities >30), GC-RMA enabled the identification of low abundance transcripts (probe intensities between 10 and 30). For instance, Septin 1 (signal intensity of 10.03) was identified by GC-RMA but not by RMA analysis (supplemental List S4A, available at www.jneurosci.org as supplemental material) and was validated as present in growth cones by Q-PCR (see Fig. 3). This underscores the value of using both algorithms for profiling growth cone mRNAs. We have included these 958 transcripts, 444 of which currently have a known function, as present in stage 32 growth cones (supplemental List S4A, available at www. jneurosci.org as supplemental material). The remaining 514 genes have as yet no ascribed function primarily because the $X$. laevis genome is not completely sequenced. The analysis, nevertheless, revealed a surprising complexity in the population of growth cone mRNAs.

\section{Composition of mRNA pool in growth cones based on gene function}

All 444 known genes were classified based on potential function (Fig. 2A) (supplemental List S5, available at www. jneurosci.org as supplemental material). The category with the largest number of genes represented was protein synthesis and translation (31\%), followed by metabolic/glycolytic (14\%) (Fig. 2A). Of particular note, transcripts encoding the majority (69 of 80 ) of the small and large subunit ribosomal proteins 
A

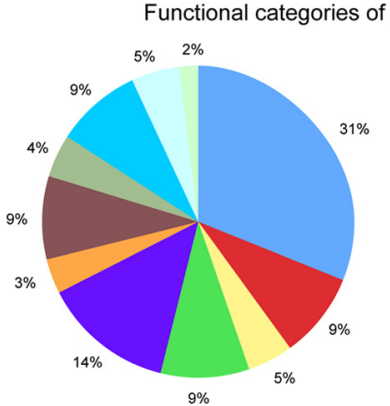

B

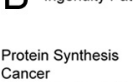

Cancer

Gastrointestinal Disea
Respiratory Disease

Tumor Morpho
Cell Cycle

Skeletal and Muscular Disorders

Neurological Disease

Cellular Growth and Proliferation Cell Death

Connective Tissue Development and Function

Cellular Development

Cell Morphology

Cellular Assembly and Organization

Hematological System Developm
Endocrine System Disorders
Cellular Function and Maintenance

Cellular Compromise

DNA Replication, Recombination, and Repair Nervous System Development and Function Hepatic System Disease Gene Expression Lipid Metabolism

$\begin{array}{ll}\begin{array}{l}\text { Cellular \& Physiological Function } \\ \text { P-value }\end{array} & \text { No. of molecules } \\ 2.47 \mathrm{E}-26 & 61 \\ 2.26 \mathrm{E}-14 & 119 \\ 1.09 \mathrm{E}-13 & 62 \\ 1.47 \mathrm{E}-07 & 25 \\ 2.53 \mathrm{E}-05 & 11 \\ 5.77 \mathrm{E}-05 & 26 \\ 5.77 \mathrm{E}-05 & 37 \\ 1.70 \mathrm{E}-04 & 20 \\ 2.16 \mathrm{E}-04 & 67 \\ 2.83 \mathrm{E}-04 & 74 \\ 4.47 \mathrm{E}-04 & 28 \\ 5.51 \mathrm{E}-04 & 56 \\ 5.51 \mathrm{E}-04 & 20 \\ 5.59 \mathrm{E}-04 & 32 \\ 5.59 \mathrm{E}-04 & 37 \\ 5.59 \mathrm{E}-04 & 10 \\ 8.86 \mathrm{E}-04 & 11 \\ 9.92 \mathrm{E}-04 & 24 \\ 0.001 & 20 \\ 0.001 & 4 \\ 0.001 & 22 \\ 0.002 & 12 \\ 0.002 & 41 \\ 0.002 & 9 \\ 0.002 & 16\end{array}$

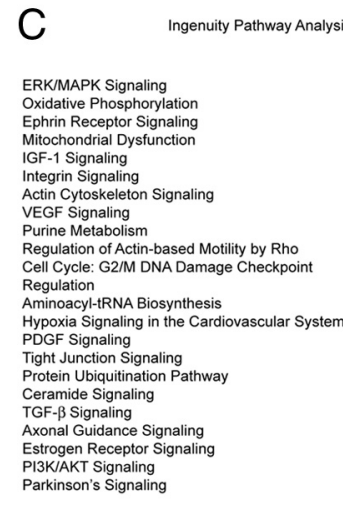

- Protein synthesis and translation $=31 \%$

- Cytoskeleta//Motor $=9 \%$

Protein degradation and apoptosis $=5 \%$

- Signaling (intracellular) $=9 \%$

Metabolic/glycolytic $=14 \%$

- Membrane trafficking (endocytosis and exocytosis) $=3 \%$

- Transmembrane and cell surface receptors $=9 \%$

Secreted and extracellular matrix $=4 \%$

- Transcription factors $=9 \%$

Nuclear $=5 \%$

Cell cycle $=2 \%$

Figure 2. Microarray and IPA of growth cone transcripts. A, Xenopus stage 32 growth cone mRNAs identified by microarray analysis were manually classified into different functional categories based on NCBI Gene tool. In total, 958 transcripts were identified, of which 444 have a known function. The pie chart represents the classification of these $444 \mathrm{mRNAs}$. B, IPA reveals the top 20 most enriched biological functions represented by the 444 growth cone mRNAs. $p<0.05$. C, Table of significant biological pathways involving growth cone mRNAs generated by IPA.

(RPs) were present (Table 1) (supplemental List S5, available at www.jneurosci.org as supplemental material). In addition, mRNAs encoding several translation initiation and elongation factors, mRNA processing, and molecular chaperones involved in protein folding were detected (Table 1) (supplemental List S5, available at www.jneurosci.org as supplemental material). The metabolic category included several enzymes, including mitochondrial ATP synthase subunits, cytochrome coxidase subunits, and metal-binding proteins such as Ferritin and Selenoproteins. The cytoskeletal/motor (e.g., $\beta$-actin, $\alpha$ - and $\beta$-tubulin, Stathmin 2 , KIF1A), signaling (e.g., RhoA), transmembrane/cell surface receptor (Laminin receptor 1, EphB4 receptor), and transcription factor (TF) (e.g., TAF1- $\beta$, Pax 2 ) categories were equally represented ( $9 \%$ for each category) (Fig. 2A). A smaller percentage of genes belonged to protein degradation and apoptosis (5\%) (e.g., Ubiquitin C, proteosome subunits), secreted and extracellular matrix (ECM) molecules (4\%) (e.g., BMP, TIMP3, ephrin A3), membrane trafficking (3\%) (e.g., Reticulon 1 and 3, Fucolectin), nuclear (5\%) (Histone 2 and $3 \mathrm{~A}$, Synculein- $\gamma$ ), and the cell-cycle machinery (2\%) (Cyclin B1, E1, Mad3) (Fig. 2A; Table 1).

To determine systematically the biological pathways represented by growth cone mRNAs, the IPA tool was used to conduct statistical tests for genes enriched in the IPA canonical pathway database. Thus, all known genes were IPA classified on the basis of molecular, cellular, and physiological function, and, in agreement with the manual classification, protein synthesis was determined as the major functional category (Fig. $2 B)$. Interestingly, several mRNAs identified are involved in diseases such as cancer, respiratory, skeletal and muscular disorders, and neurological diseases (Fig. $2 B$, list of top 20 functional categories) (supplemental List S6A, complete list of functional categories, available at www. jneurosci.org as supplemental material). Some unexpected categories appear on the list, such as gastrointestinal disease, DNA replication, recombination, and repair. This is because IPA assigns each gene to multiple categories resulting in some categories, such as recombination and repair and gastrointestinal disease, being defined by only a few genes. The majority of these genes (e.g., Myc, KRAS, Tpt1, stathmins) overlap with the cancer category that forms the second largest functional category (supplemental List S6 A, available at www.jneurosci.org as supplemental material). Additional analysis of the individual mRNAs into different biological pathways showed extracellular signal-regulated kinase (ERK)/mitogen-activated protein kinase (MAPK) signaling, oxidative phosphorylation, and ephrin signaling, among others, as the most enriched biological pathways for growth cone mRNAs (Fig. 2C) (supplemental List $S 6 B$, available at www.jneurosci.org as supplemental material). Overall, the results showed that growth cones contain a surprisingly wide range of different mRNA transcripts pointing to the possibility that many different functional types of proteins can be locally synthesized.

\section{Validation of microarray data using Q-PCR and FISH}

To validate the microarray data, we used two approaches: Q-PCR and FISH. A panel of 40 transcripts was selected for validation by Q-PCR. These transcripts were identified as present from the microarray screen and were selected to represent mRNAs broadly across the different functional categories, with different array intensities and with a partial focus on genes with known axon guidance function. For both biological and technical confirmation, RNA samples from independent batches of laser-captured growth cones $(\sim 1000$ growth cones per sample, $n=3)$ were used as templates for Q-PCR. Of the 40 genes analyzed, 38 were Q-PCR positive, and the results showed good inter-platform correlation: genes with high intensity signals on the microarray (GCRMA), indicative of high expression levels, exhibited low CT values, whereas those with low array intensity showed high CT values (Fig. 3A). For example, ribosomal proteins such as RPL35a and RPS13 had high signal intensities on the array (Fig. 3B) (supplemental List $S 4 A$, available at www.jneurosci.org as supplemental material) and low CT values, and these were linearly input dose dependent in all three biological replicates. Of the 38 genes, the CT values of 20 transcripts from different functional categories showed tight correlation between input and PCR amplification (supplemental List S2 A, available at www.jneurosci.org as supplemental material) (see Materials and Methods). The remaining 18 transcripts (e.g., Fucolectin) with high CT values sometimes failed to show input PCR amplification consistency and were often associated with greater biological variability between the three replicates (supplemental List S2 A, available at www.jneurosci.org as supplemental material). Two of the 40 selected transcripts, ephrin A3 and histocompatibility 13, 
Table 1. Key examples of transcripts of diverse biological functions identified in Xenopus stage 32 and stage 24 growth cones and mouse E16 growth cones

\begin{tabular}{|c|c|c|c|}
\hline & Xenopus stage 24 & Xenopus stage 32 & Mouse E16 \\
\hline \multicolumn{4}{|l|}{ Protein synthesis and translation } \\
\hline \multirow[t]{4}{*}{ RPs } & $\begin{array}{l}\text { Large RPs: L5, L7-15, L17-19, L21-24, L27-28, } \\
\text { L30-31, L35-38, P0, P1, and P2 }\end{array}$ & $\begin{array}{l}\text { Large RPs: L4-5, L7-15, L17-19, L21-24, L27-31, } \\
\text { L34-38, L41, P0, P1, P2 }\end{array}$ & $\begin{array}{l}\text { Large RPs: L3-19, L21-24, L26-32, L34-39, L41, P0, } \\
\text { P1, and P2 }\end{array}$ \\
\hline & \multirow[t]{3}{*}{ Small RPs: S1-6, S8-21, S23, S25-29 } & \multirow{2}{*}{$\begin{array}{l}\text { Small RPs: S1-6, S8-21, S23, S25-29, RP small } \\
\text { subunit }(28.1 \mathrm{kDa}) \text { (rps-6) }\end{array}$} & Small RPs: S2-21, S23-29 \\
\hline & & & Mitochondrial RPs: L11, L13, L23, L30, L33, L34, L50, \\
\hline & & Mitochondrial RPs: L41 & $\mathrm{L} 51, \mathrm{~L} 52, \mathrm{~L} 54, \mathrm{~S} 18 \mathrm{C}$ \\
\hline Translation regulation & EF1, elF-5A, IF3 & $\mathrm{EF} 1$, EF2, elF-5A, IF3, IF2 & EF1, elF1, elF3, elF-5A \\
\hline mRNA processing & Sfrs2, Sfrs15, Sf3a2, MLN51 & Sfrs2, Sfrs15, Sf3a2, MLN51, Ski2 & $\begin{array}{l}\text { Sf1, Sfrs2, Sfrs3, Sf3b4, Ybx1, Fubp3, Aco1, Stau1, } \\
\text { PABPc1 }\end{array}$ \\
\hline $\begin{array}{l}\text { Nascent protein processing/ } \\
\text { folding }\end{array}$ & CypA, Hsp70, Fkbp10 & CypA, Hsp70, Hsp30, SSB1, Fkbp10 & Cct4, Cct2, Hsp17, Hsp1, Hsp8, Hsp14, Hsp110, Fkbp3 \\
\hline \multicolumn{4}{|l|}{ Cytoskeletal/motor } \\
\hline Cytoskeletal components & $\alpha$-Tubulin, $\beta$-tubulin 2 & $\beta$-Actin, $\alpha$-tubulin, $\beta$-tubulin 2, 4 & $\beta$-Actin , $\alpha$-tubulin 1A, B, C, $\beta$-tubulin 2b, 5 \\
\hline $\begin{array}{l}\text { Cytoskeletal interacting } \\
\text { proteins }\end{array}$ & TMSB4X, Pfn2, Coro1c, Stmn2, Sdcbp, GAP43 & $\begin{array}{l}\text { TMSB4X, ARP2, Arpc1a, Stmn3, Stmn2, GAP43, } \\
\text { EB1, EB2, Fascin, Paxillin (Pxn) }\end{array}$ & $\begin{array}{l}\text { Tmsb10, Cfl1, Stmn1, Stmn2, Stmn3, GAP43, Gsn, } \\
\text { Tbca, Tbcb, TMSB4x, APC, Enah, ARP2, Arpc2, Vil2, } \\
\text { Kalrn, Detn2, MAP1lc3a, Flna, EB1, EB2, Pxn }\end{array}$ \\
\hline Motors & Dnal4, Mhc-A, Myh4 & KIF1A, dlc8a, Mylc2a, Mhc-A, Myh10 & $\begin{array}{l}\text { Myl6, Mylc2b, Myh9, Dynlt1, Dynll1, kns2, KIF5B, } \\
\text { KIF5C }\end{array}$ \\
\hline Protein degradation and apoptosis & Ubc, Tpt1, Proteosome subunits, Tegt & $\begin{array}{l}\text { Ubc, Ube2n, Ube2e1, Ube2c, Tpt1, Proteosome } \\
\text { subunits, Smurf2 }\end{array}$ & $\begin{array}{l}\text { Ubb, Ubc, Tpt1, Proteosome subunits, Usp7, Bap1, } \\
\text { Ngfrap1, Phr1, Siva1, Tradd, Dad1, Ube2f, Ube2q1, } \\
\text { Ube2z, Ube2d2 }\end{array}$ \\
\hline Signaling & $\begin{array}{l}\text { 14-3-3, Ck2b, Phospholipase A2-activating pro- } \\
\text { tein, Kras-A, PP2A }\end{array}$ & $\begin{array}{l}\text { 14-3-3, Kras-A, Ckle, CK2, PKC-delta2, } \\
\text { Map2k1ip1, RhoA, Septin } 1\end{array}$ & $\begin{array}{l}\text { 14-3-3, MAP3K12, Csnk1a1, Anx3, MAPK9, Camk1d, } \\
\text { Camk2d }\end{array}$ \\
\hline Metabolic & Ftn, ATPase synthase subunits, CS, Nduf subunits & $\begin{array}{l}\text { Ftn, ATPase synthase subunits, COX subunits, } \\
\text { Seli, CS, Nduf subunits }\end{array}$ & $\begin{array}{l}\text { Ftn, COX subunits, ATPase synthase subunits, Gstp1, } \\
\text { Nduf subunits, CS }\end{array}$ \\
\hline Membrane trafficking & Rtn1, Ykt6b, Adaptor related protein complex 2 & $\begin{array}{l}\text { Rtn1, Rtn3, TAP binding protein, Vacuolar } \\
\text { protein sorting 4a, Fucolectin, Srl }\end{array}$ & Fez2, Ap2a2, Clta, RAB2, RAB1B, Sec61b, Rtn 3 \\
\hline Transmembrane/receptors & $\begin{array}{l}\text { Ig rearranged heavy and light chains, Aquaporin, } \\
\text { MHC II, VDAC2, Lamr1 }\end{array}$ & $\begin{array}{l}\text { Ig rearranged heavy and light chains, Tcra-A, } \\
\text { Lamr1, MHC class II, Dag1, CD81 antigen, } \\
\text { EphB4, Porin, } \mathrm{Na}^{+}, \mathrm{Ca}^{2+}, \mathrm{K}^{+} \text {channels, } \\
\text { VDAC2 }\end{array}$ & $\begin{array}{l}\text { Ldlrad3, Smo, Klhl17, Ctnnbl1, L1CAM, Sypl, tet- } \\
\text { raspanin 31,33, CD24a, CD55, CD74 antigens, } \\
\text { Protocadherins 9, } \beta 14, \gamma 3 \text { and } \alpha 11 \text {, Integrins } \\
\alpha 9, \alpha 3 \text { and } \beta 1 \text {, Dag1, } \mathrm{Na}^{+}, \mathrm{Ca}^{2+}, \mathrm{K}^{+} \text {channel, } \\
\text { VDAC2, Aquaporin } 3 \text { and 6, Sv2a, Syt16, Gpc4, } \\
\text { Neurotrimin, Nlgn1, Dlpag1, Nrp2 }\end{array}$ \\
\hline Secreted and ECM & $\begin{array}{l}\text { BMP/Xtld, FSTL1, TIMP3, Shc1, growth factor } \\
\text { Livertine }\end{array}$ & $\begin{array}{l}\text { BMP/Xtld, FSTL1, TIMP3, efna3, efnb2a, Shc1, } \\
\text { Col1a1 }\end{array}$ & $\begin{array}{l}\text { FSTL1, TNF-8, Grn, Lgals1, Col8a1, Sema3a, Sema6C, } \\
\text { Ntng1, Lamb1-1, Lamb2, Nrg3, Shh }\end{array}$ \\
\hline Transcription factors & Xnot, TAF1- $\beta 2$, Hspb1a & TAF1- $\beta$, Xnot, Pax 2, Rx1a, Myc II & TAF10, Myc2, Crebzf \\
\hline Nuclear & $\mathrm{H} 3$, Sncg, Sf3b1, maternal G10 transcript & $\mathrm{H} 3 \mathrm{a}, \mathrm{H} 2$, N038, Sncg & RAN, Morfl2, H2, H3a, Ranbp5, Ranbp10, Nol5a, LmnA \\
\hline Cell cycle & & Cyclin B1, L2, E1, F, Mad3 & $\begin{array}{l}\text { Anapc5, Anapc13, cyclins I, G1, A1, D1, E1, Cetn2, } \\
\text { Pttg1, Clk1, Cdk2ap1 }\end{array}$ \\
\hline
\end{tabular}

failed to produce a single amplicon from whole-eye total RNA (see Materials and Methods) and were not analyzed further (data not shown). Overall, the Q-PCR results validated 38 of 40 transcripts, confirming the reproducibility of the microarray data.

Next we performed FISH on growth cones combined with quantitative fluorescence intensity analysis on a subset of the transcripts that had been validated by Q-PCR (21 of 38). We selected 21 mRNAs to represent a range of signal intensity values on the array and to sample the various functional categories. The mean fluorescence (pixel) intensity per unit area was calculated for each growth cone (20-30 per probe condition and three experimental replicates), and statistical comparison of values obtained with the antisense versus sense probes was used to evaluate specificity and determine whether the transcript was present (Fig. $4 A$ ). In growth cones with a positive hybridization signal, the antisense probe showed a bright punctate signal (Fig. 4C-O), whereas the sense controls had very little or no signal (data not shown). Overall, 62\% (13 of 21) of the Q-PCR-validated mRNAs were validated as present in growth cones by FISH (Fig. 4). The remaining eight mRNAs mostly had low array intensity values and, although validated by Q-PCR, did not give a detectable hybridization signal by FISH (data not shown). The lower sensitiv- ity of FISH is expected given the lower amount of amplification used with this method. No signal was detected for glyceraldehyde-3-phosphate dehydrogenase (GAPDH) mRNA in growth cones (Fig. $4 B$ ), which is in good agreement with the Q-PCR results (supplemental List S2 A, available at www.jneurosci.org as supplemental material).

FISH not only provides a validation of the array data but also gives spatial information about the form and distribution of the transcripts. For all mRNAs examined, individual puncta were located primarily in the central domain of the growth cone and occasionally more peripherally in the filopodia, usually in the proximal portion. The signal for some mRNAs consisted of large-sized puncta that were sparsely distributed such as Thymosin $\beta 4$, Ribosomal protein S13 (RP S13), Ferritin, Ubiqutin C, and Histone H3 [Fig. 4, see insets for RP S13 (E) and Ferritin (K) mRNAs]. In contrast, the signal for other mRNAs, such as ephrinA3 and $\alpha$-tubulin (Fig. $4 C, M$, respectively), was represented by a larger number of smaller granules (see insets). The punctate nature of the FISH signal and the variable granule sizes suggest that different mRNAs may be associated with different types of ribonucleoprotein particles (Kiebler and Bassell, 2006). 
A

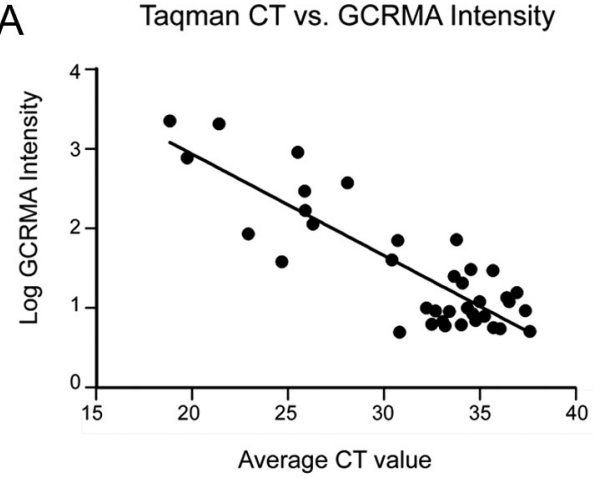

B

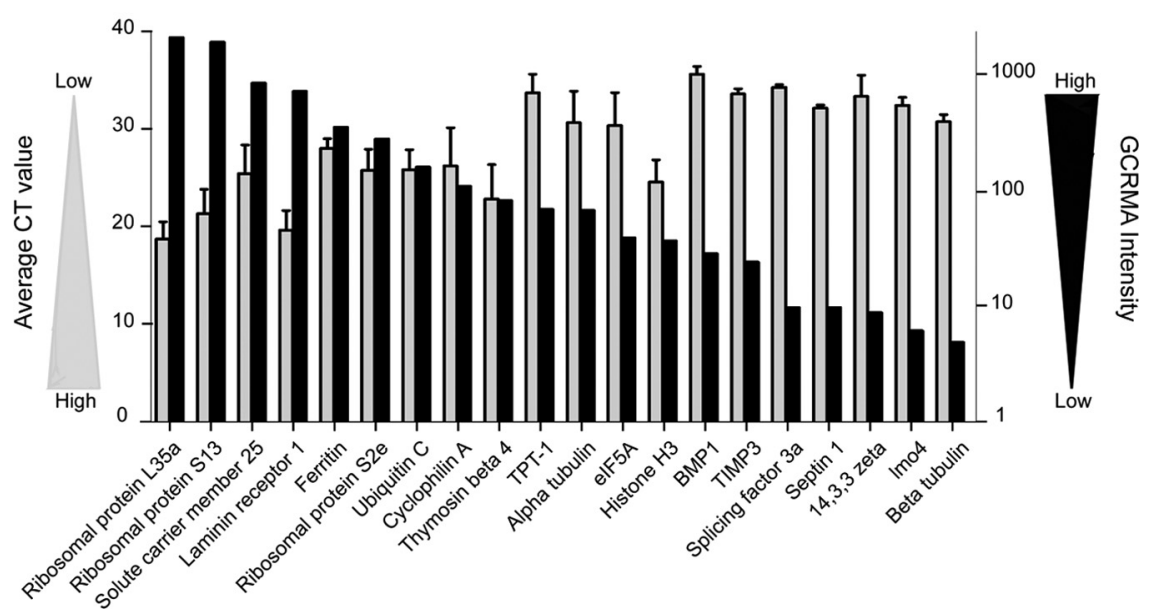

Figure 3. Q-PCR validation demonstrates inter-platform reproducibility. Scatter plot representation of log GC-RMA intensity versus average CT value of all 38 transcripts tested for validation of the microarray data by $Q-P C R(A)$. Inverse correlation between average CT value and GC-RMA intensity is shown in greater detail for 20 (of the 38) transcripts that had relatively high microarray signal intensities. These 20 transcripts also showed a tight correlation between input and PCR amplification (for details, see Materials and Methods) (B). (T values represent the number of cycles at which threshold was passed (thus inversely correlate to expression level), and error bars represent \pm SEM.

Together, the microarray profiling with two different validation methodologies revealed a broad spectrum of functional mRNAs in growth cones. However, we cannot completely rule out the possibility of missing some important transcripts by our analysis. Moreover, the results broadly confirmed the specificity and sensitivity of the unbiased screen in identifying growth cone transcripts especially of low abundance that would go undetected by classical candidate approaches, such as FISH.

\section{Growth cone mRNAs increase in number and complexity in $24 \mathrm{~h}$ of development}

Growth cones of RGCs show marked changes that follow a stereotyped sequence in their responsiveness to guidance cues during the $24 \mathrm{~h}$ period after axon initiation (Campbell et al., 2001; Shewan et al., 2002). One way to generate different growth cone responses is to alter the composition of the local proteome through dynamic changes in mRNA localization. Therefore, we asked whether the pool of growth cone mRNAs is dynamically regulated over time. We performed a genomewide screen on young growth cones, similar to that performed on old stage 32 growth cones, followed by comparative profiling. Young growth cones were collected by LCM from stage 24 eye primordia (preaxonogenesis) cultured for $17 \mathrm{~h}$, which correlates with the time when pioneer growth cones reach the optic chiasm/ventral optic tract in vivo (Holt, 1984). These growth cones were $\sim 24 \mathrm{~h}$ younger than those classified as old collected from stage 32 eyes in the above analysis (Fig. 5A). Microarray profiling of mRNA was done in the same way for both ages. Compared with the 958 genes identified in old growth cones, far fewer transcripts were identified in young growth cones: RMA detected 63 mRNAs (all of which were also detected by GC-RMA), and GC-RMA detected an additional 223 mRNAs, resulting in a total of 286 genes (supplemental Fig. S3B, available at www. jneurosci.org as supplemental material), 171 of which have known function (supplemental List $S 4 B$, available at www. jneurosci.org as supplemental material). Young growth cones, therefore, contain only $30 \%$ of the number of mRNAs found in old growth cones, suggesting that an increasing number of mRNAs are trafficked into growth cones as they advance away from the cell body. It is of interest to note that this finding argues against the possibility that growth cone mRNAs are simply a "spillover" from the cell body because, if this was the case, more transcripts would be predicted to reside in young growth cones, which are closer to the soma.

Functional analyses (IPA and manual) showed that the majority of the mRNAs present in young stage 24 growth cones belonged to the protein synthesis category (Fig. 5B) (supplemental Lists $\mathrm{S} 6 C, D, \mathrm{~S} 7$, available at www.jneurosci.org as supplemental material) because most transcripts encoded ribosomal proteins (62 of 80) (Table 1). Other functional categories were similar to what was found in old growth cones, including cancer, respiratory disease, and neurological disease (supplemental List S6C, available at www.jneurosci.org as supplemental material). However, only four significant biological pathways were represented in the young growth cone mRNAs, of which oxidative phosphorylation is the most enriched pathway (supplemental List $S 6 D$, available at www.jneurosci.org as supplemental material), in contrast to the old growth cone repertoire that is represented by 22 biological pathways (Fig. 2C) (supplemental List $6 B$, available at www.jneurosci.org as supplemental material). Manual categorization further revealed that the protein synthesis category comprised a significantly larger proportion of the total mRNA repertoire of young versus old growth cone (53 vs 35\%) (Fig. 5C) (supplemental Lists S5, S7, available at www. jneurosci.org as supplemental material). Because the genes represented in this category (e.g., ribosomes, translation initiation factors, and chaperones) are similar in the two ages, this reflects the upregulation of new classes of mRNAs in old growth cones, such as signaling, metabolic, transmembrane and cell surface receptors, and transcription and nuclear factors (Fig. $5 C$, indicated by arrows).

The majority $(66 \%)$ of the mRNAs present in young growth cones were also present in old growth cones as indicated by the overlap of 226 mRNAs in the Venn diagram representation (Fig. $5 D$ ). Of the 60 transcripts that appear exclusively in young 
growth cones, 28 have a known function (Fig. 5B) (supplemental List S7, available at www.jneurosci.org as supplemental material). For example, the actin-regulating proteins profilin II and Coronin were detected in young but not in old growth cones. Both molecules are important for cell motility and crosstalk between the actin and microtubule cytoskeleton (Goode et al., 2000) Thus, young growth cones en route may need a local source of these proteins to modulate their motility. Notably, young growth cones lack mRNAs encoding transmembrane and secreted proteins associated with synapse formation (see Table 3 ). Thus, within $24 \mathrm{~h}$ of development, the mRNA composition in growth cones is altered dynamically from an initial relatively simple set of mRNAs predominantly encoding protein synthesis machinery during pathfinding to a more complex repertoire that includes, for example, mRNAs encoding proteins important for synapse formation.

\section{Ephrin signaling pathway exclusively in} old growth cones

Ephrin receptor signaling was identified as one of the most upregulated signaling pathways in stage 32 growth cones ( $p=$ $2.19 e-03$ ) (Fig. 5E) but was absent from young growth cones (supplemental List $6 D$, available at www.jneurosci.org as supplemental material). Ephrin signaling is an important pathway expected for old growth cones because it occurs during target innervation and is important for topographic mapping (Drescher et al., 1997; Flanagan and Vanderhaeghen, 1998; Hindges et al., 2002; Mann et al., 2002, 2003; Flanagan, 2006) and synapse formation (Lim et al., 2008; Lai and Ip, 2009). This Xenopus microarray screen identified EphB4, ephrinB2, and ephrinA3 mRNAs exclusively in old (stage 32 ) but not in young (stage 24) growth cones. To validate the age-specific localization, we performed FISH of EphB4 mRNA in old and young growth cones. Old stage 32 growth cones showed a clear signal for EphB4 mRNA that occurred in distinct granules, whereas no signal was detected in young stage 24 growth cones (Fig. $5 F, G$ ).

The upregulation of ephrin receptor signaling in old growth cones could be attributable to a timedependent switch in either transcription or mRNA localization. To distinguish between these two possibilities, we reasoned that mRNA would be absent in young RGC somas if a transcriptional mechanism was responsible (i.e., late switch-on of ephrin genes) but present if developmentally regulated mRNA localization was the dominant mechanism. Therefore, we asked whether EphB4 mRNA is expressed in the cell bodies of RGCs at both stages of development by performing Q-PCR on mRNA from LCMin $\boldsymbol{E}$ inset, $0.5 \mu \mathrm{m})$.
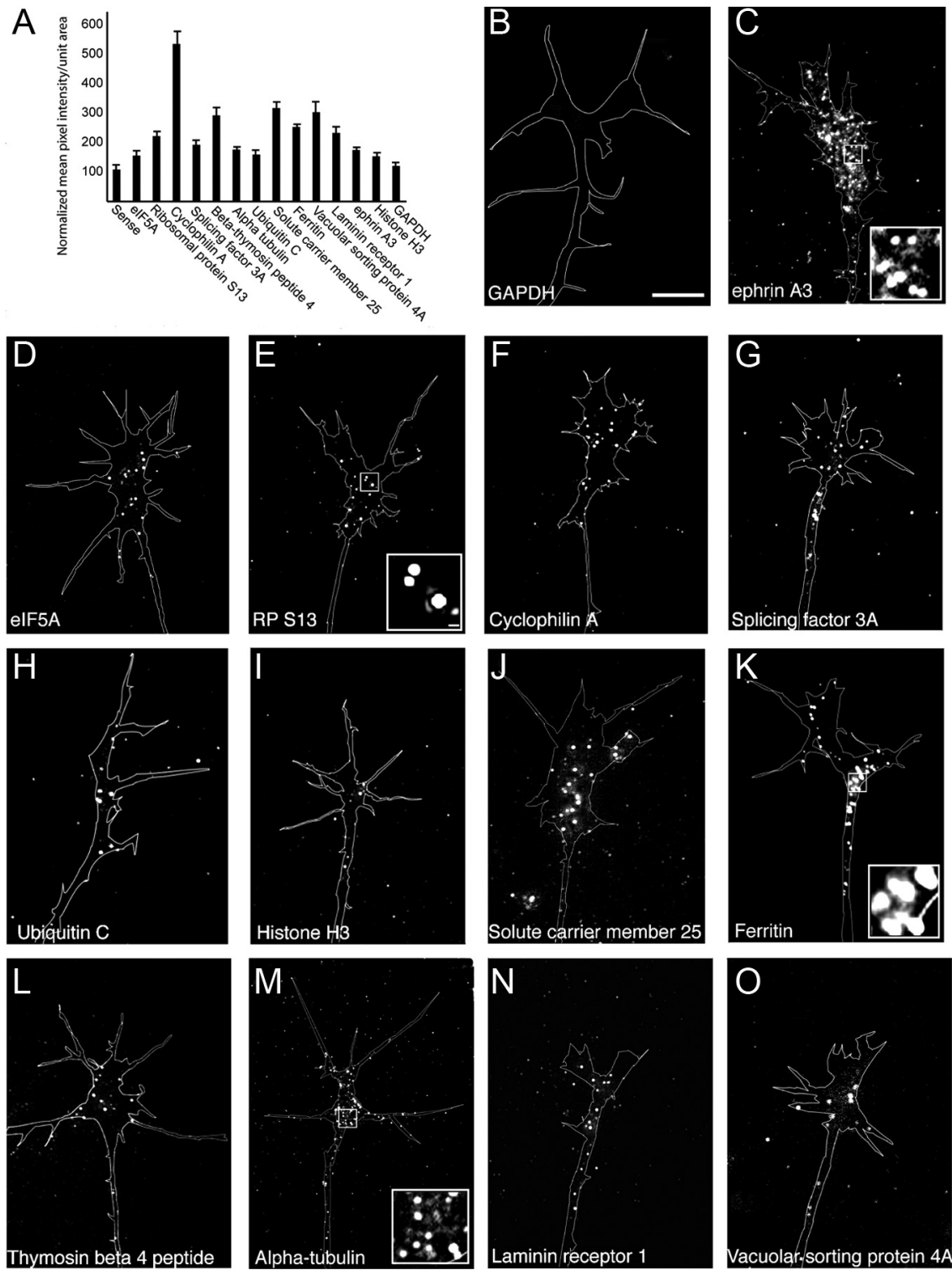

Figure 4. FISH validation of mRNAs in growth cones. $\boldsymbol{A}$, Quantitative FISH (see Materials and Methods) was performed on stage 32 Xenopus growth cones to obtain the mean pixel (fluorescence) intensity/unit area of antisense signal. Corresponding sense probes were used as controls for signal specificity, and all antisense mean pixel intensity/unit area were normalized to the sense control. The mRNAs chosen sample broadly across the different functional categories identified by the microarray analysis. Transcripts validated include ephrin A3 (C) (secreted and ECM category); elF5A (D), Ribosomal protein S13 $(\boldsymbol{E})$, Cyclophilin A $(\boldsymbol{F})$, and Splicing factor $3 A(\boldsymbol{G})$ (protein synthesis and translation category); Ubiquitin $C(\boldsymbol{H})$ (protein degradation and apoptosis category); Histone H3 (I) (nuclear category); Solute carrier member $25(\boldsymbol{J})$ and Ferritin $(\boldsymbol{K})$ (metabolic/glycolytic category); Thymosin $\beta 4$ peptide $(\boldsymbol{L})$ and $\alpha$-tubulin $(\boldsymbol{M})$ (cytoskeletal/motor category); and $67 \mathrm{kDa}$ Ribosomal protein/Laminin receptor $1(\boldsymbol{N})$ and Vacuolar sorting protein $4 \mathrm{~A}(\boldsymbol{0})$ (transmembrane/cell surface receptor and membrane trafficking categories, respectively). GAPDH mRNA was absent in growth cones and served as a negative control (B). Scale bar, $5 \mu \mathrm{m}$. Insets in boxed areas at higher magnification show differences in granule size and density (scale bar

isolated RGC cell bodies of young and old retina (see RGC cell body isolation in Materials and Methods). The Q-PCR data showed that EphB4 mRNA is expressed at similar levels at both stages (Fig. $5 H)$. This indicates that the EphB4 gene is transcribed in both young and old RGCs, but the transcripts remain confined to young somas and do not localize to the growth cone until later. This suggests that at least some of the differences in the repertoire of old and young growth cones may be attributable to a developmentally regulated mechanism of transcript transport and localization. 
A
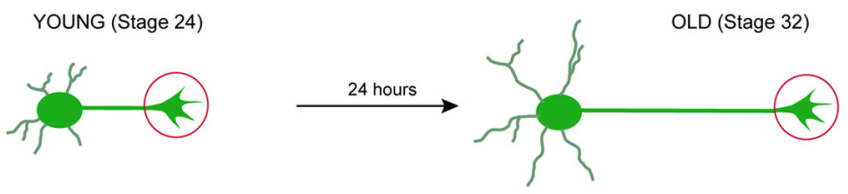

B
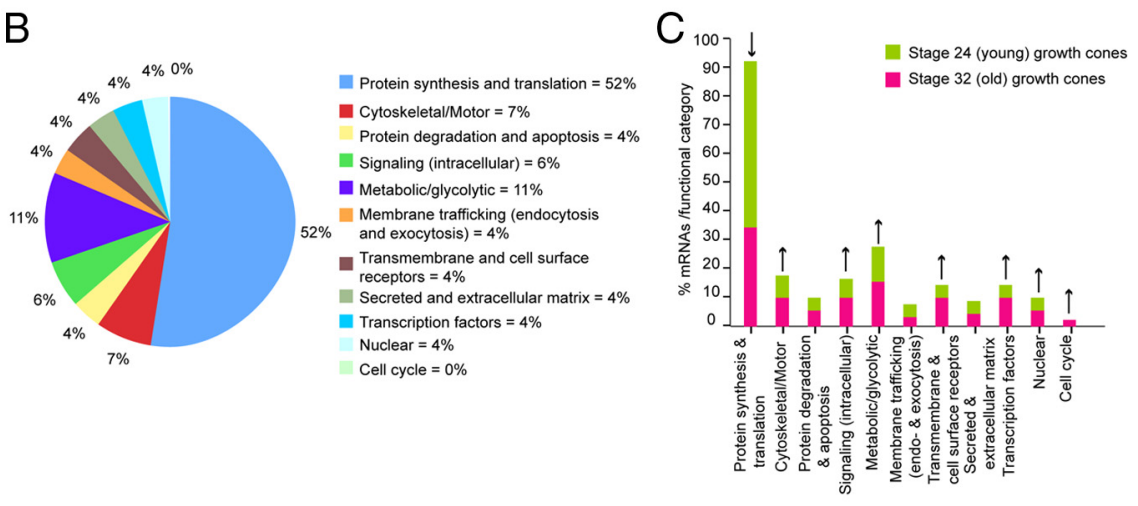

D

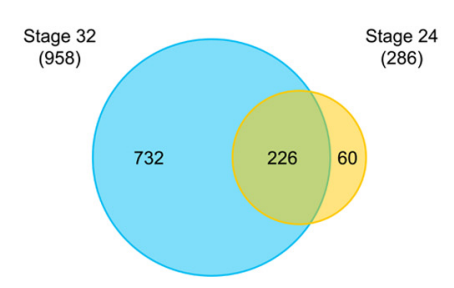

$\mathrm{F}$

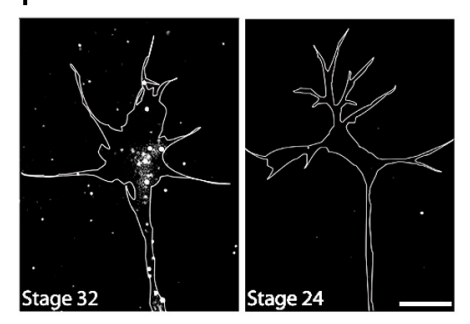

$\mathrm{E}$ Biological pathways upregulated in stage 32 (old growth cones) Pathway Oxidative Phosphorylation $\quad 1.35 \mathrm{E}-04$ ERK/MAPK Signaling 1.95E-04 Ephrin Receptor Signaling Regulation of Actin-based Motility by Rho Regulation of Actin-based Motily by Rho 2.57E-03 Tight Junction Signaling Aminoacyl-tRNA Biosynthesis Mitochondrial Dysfunctio Integrin Signaling
Actin Cytoskeleton Signaling Actin Cytoskeleton Signaling
Protein Ubiquitination Pathway Protein Ubiquitination
Purine Metabolism Hypoxia Signaling in the Cardiovascular System Cell Cycle: G2/M DNA Damage Checkpoint Regulation TR/RXR Activation VEGF Signaling

G

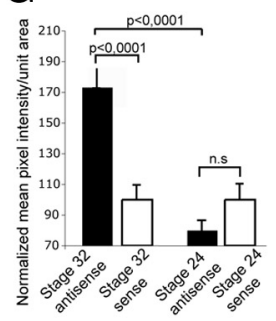

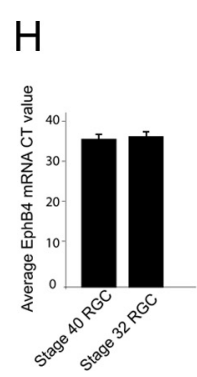

Figure 5. Growth cone mRNA repertoire is developmentally regulated: transcript number and complexity increases in $24 \mathrm{~h}$. $\boldsymbol{A}$, Schematic showing LCM collection of young stage 24 and old stage 32 growth cones. $\boldsymbol{B}$, mRNAs identified in stage 24 growth cones were manually classified into different functional categories using NCBI Gene tool. In total, 286 mRNAs were identified of which 171 transcripts have a known function. The pie chart represents the functional classification of these 171 mRNAs. C, Comparison of functional classes of mRNAs between old (Fig. $2 A$ ) and young $(\boldsymbol{B})$ growth cones shows that most categories of mRNAs are upregulated with age (upward arrow), except for transcripts involved in protein synthesis and translation, demonstrating the increasing complexity of the growth cone mRNA pool with development. $\boldsymbol{D}$, Comparative profiling shows that young growth cones have far fewer mRNAs than old growth cones (286 vs 958) and that the degree of overlap is $80 \%$. E, IPA identified pathways that are specifically upregulated in stage 32 old versus stage 24 young growth cones. $\boldsymbol{F}$, EphB4 mRNA localization in stage 32 growth cones was confirmed by fluorescence in situ hybridization. $\mathbf{G}$, The specificity of the fluorescence signal was calculated by the mean pixel (fluorescence) intensity/unit area of antisense signal compared with its corresponding sense signal ( $n=3$ for each group). Statistical analysis performed using the Kruskal-Wallis test. Scale bar, $5 \mu \mathrm{m} . \boldsymbol{H}$, Q-PCR results for EphB4 mRNA in LCM-isolated RGC cell bodies of old (stage 40) and young (stage 32 ) retina indicating similar expression levels at both developmental stages ( $n=4$ for each stage).

\section{Subcellular profiling reveals significant differences in axon versus growth cone compartments and identifies a subset of mRNAs enriched in the growth cone}

Because the growth cone is functionally distinct from the axon, we asked whether the mRNA populations differ between the two cellular compartments. To test this, stage 32 Xenopus RGC axon shafts, without growth cones, were laser captured by LCM, and the mRNA was extracted and subjected to microarray analysis in the same way as growth cone mRNA (Fig. 6A). RMA and GC-RMA analysis together identified 5105 transcripts present in axons (supplemental List S8A, available at www.jneurosci.org as supplemental material). This number is consistent with the number of transcripts found in unbiased screens of other types of axons (e.g., 3000-11,000 transcripts) (Andreassi et al., 2010; Gumy et al., 2010) and is significantly more ( $81 \%$ ) than the number of transcripts found in growth cones. IPA showed that protein synthesis, cancer, respiratory disease, and nervous system development and function constituted the major functional categories of axonal mRNAs, which were also seen for the growth cone mRNA pool (supplemental List $S 8 B$, available at www.jneurosci.org as supplemental material). Oxidative phosphorylation, ephrin receptor, and actin cytoskeleton signaling among others were the major biological pathways (supplemental List S8C, available at www.jneurosci.org as supplemental material), yet there were some interesting differences between axon and growth cone mRNA pools. For example, categories, such as protein trafficking, protein folding, and cell-mediated immune response, were significantly enriched in axons but not in growth cones (supplemental List S8 B, available at www.jneurosci.org as supplemental material) (Fig. 2B).

Although, as expected, many of the growth cone transcripts were also present in axons, we wondered whether we could also detect mRNAs that were specifically enriched in growth cones. Comparative profiling revealed that of the 958 growth cone genes in stage 32 growth cones (RMA plus GC-RMA analysis) (supplementalFig.S3A, availableatwww.jneurosci. org as supplemental material), 58 were at least 1.5-fold enriched in growth cones compared with axons. Conversely, 523 genes were at least 1.5-fold enriched in axons versus growth cones, and 377 genes have similar expression profiles in both axons and growth cones (supplemental List $S 8 D$, available at www.jneurosci.org as supplemental material). Of the 58 growth cone-enriched mRNAs, 28 have a known function, with the cytoskeletal-associated mRNAs comprising the largest functional category (23\%), up from $9 \%$ representation in the total population of growth cone mRNAs (compare Fig. $6 B$ with Fig. $2 A$ ). Protein synthesis and translation is still richly represented (15\%), although this is significantly lower than in the total growth cone mRNA population (31\%). Other functional categories that show increased representation in enriched versus total growth cone mRNAs are transmembrane/cell surface receptors ( 15 vs $9 \%$ ), secreted (12 vs $4 \%$ ), signaling (12 vs $9 \%$ ), and nuclear (15 vs $5 \%$ ) mRNAs. In contrast, functional categories 
with decreased representation within growth cone-enriched mRNAs compared with the total growth cone mRNA repertoire include metabolic/glycolytic (8 vs $14 \%$ ), transcription factors (0 vs $9 \%$ ), degradation ( 0 vs $5 \%$ ), cell cycle ( 0 vs $4 \%$ ), and membrane trafficking ( 0 vs $3 \%$ ) categories.

In terms of specific mRNAs, the most highly growth cone-enriched mRNA $(6.9 \times)$ encodes Ribonucleotide reductase M2 (RRM2), a molecule shown recently to promote the in vivo growth of tumor cells (Zhang et al., 2009) (Fig. 6C). Also of particular interest among the growth cone-enriched mRNAs are two microtubule end-binding proteins, EB2 $(3.8 \times)$ and EB1 (1.6×) (Fig. 6C). Other interesting examples of growth cone-enriched mRNAs include Fascin (actin bundling protein), the small GTPase RhoA, Activin receptor, Septin 1, MAPK8, ectonucleotide pyrophosphatase (autotaxin), and the tissue inhibitor of metalloproteinases 3 (TIMP3). Thymosin $\beta 4$ peptide, an actin-binding protein involved in axon outgrowth (van Kesteren et al., 2006), conversely, is 3.86-fold enriched in the axonal compartment (supplemental List $S 8 D$, available at www.jneurosci.org as supplemental material). To further validate these findings, we used FISH to compare signal enrichment in the growth cone relative to the axon proper. We selected two transcripts from the growth coneenriched list (EB1 and EB2) and one from the axon-enriched list (Thymosin $\beta 4$ peptide) (supplemental List $S 8 D$, available at www.jneurosci.org as supplemental material) and determined the MGD ratio in the growth cone versus the axon [GC/ axon (see Materials and Methods)]. For both EB1 and EB2, the MGD was significantly higher in the growth cone than the axon (EB1, GC/axon $=1.2, p=0.0336$; EB2, GC/axon $=1.3, p=0.0414$ ), whereas for Thymosin $\beta 4$ peptide, the reverse was found, with MGD significantly higher in the axon than the growth cone $(\mathrm{GC} / \mathrm{axon}=0.8, p=0.0342)$.

Intriguingly, of the enriched transcripts present in old stage 32 growth cones, TIMP 3 and MAPK8 transcripts are the only two known transcripts present in stage 24 or young growth cones (supplemental List $S 4 B$, available at www.jneurosci.org as supplemental material). This suggests that old stage 32 growth cones are enriched in mRNAs that are distinct from its axonal compartment and from younger (stage 24) growth cones. Thus, subcellular enrichment in growth cones may be developmental stage specific, with old growth cones enriched with transcripts distinct from young ones reflecting changes in growth cone function from pathfinding to synaptogenesis. However, three of the four genes showing the highest levels of enrichment in the growth cone $(6-15 \times)$ are unknown (absent from the X. laevis database),

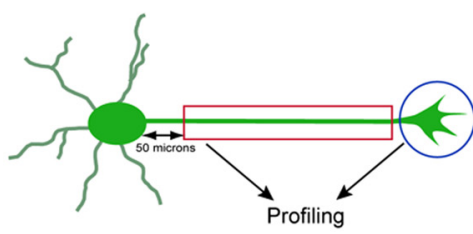

\section{B Functional categories of mRNAs specifically enriched in growth cones}
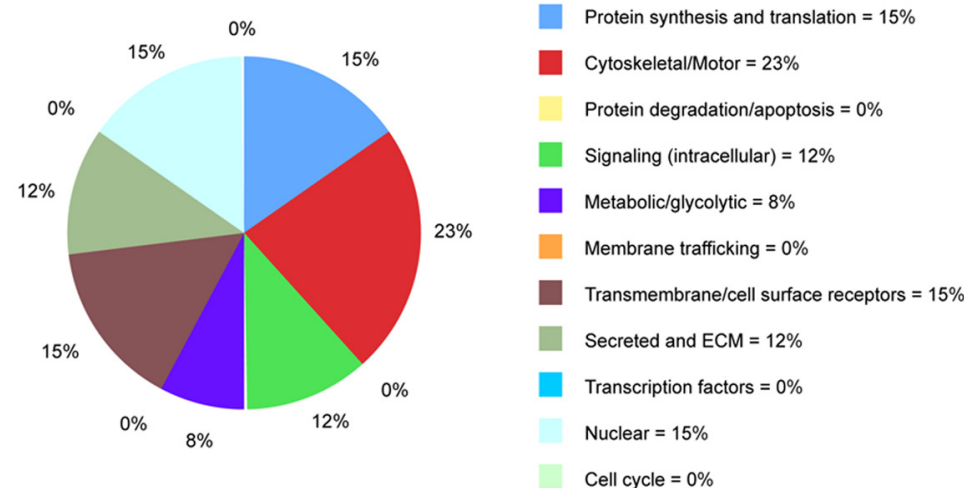

Identity of growth cone enriched mRNAs.

Growth cone/Axon signal intensity Genebank

XI.24807.1.S1_at $\quad 6.92 \quad$ BJ098060

XI.16807.1.A1_at $\quad 3.83 \quad$ BJ083816 Microtubule-associated protein, RP/EB family, member 2 (mapre2-A)

$X I 15128.151$ at

XI.4169.1.S1_at

XI.8056.1.S1_at

XI.5502.1.S1_at

XI.4617.1.S1_at

XI.21477.1.S1_at

XI.15948.1.S1_at

XI.2467.2.S1_at

XI.19100.1.A1_at

XI.25561.1.A1_at

XI.151.1.S1_at

XI.2867.2.A1_s_at

XI.4141.1.A1_at

XI.6127.1.S1_at

XI.22496.1.A1_at

XI.18672.1.A1_at

XI.13472.1.S1_s_at

XI.1083.1.S1_at

BG016907

BQ398671

BC047262

B1448163

M34080

AF515589

BE027103

BQ397922

CB560207

M24680

BG346667

BC043975

BG555066

BC046647

B1938793

BG038819

BG038467

M27254

BF025541

BC044675

BC044675

BJ081653

BE678215

BQ383424

BQ383424
BJ099031

BJ09903
S47891
Description

fusion, derived from $t(12 \cdot 16)$ malignant liposarcoma (human) (fus) Eukaryotic translation initiation factor 3 subunit 10

polymerase (DNA directed), delta 2, regulatory subunit $50 \mathrm{kDa}$ (pold2) Xenopus tropicalis polymerase (RNA) II (DNA directed) polypeptide D (Polr2d) proliferating cell nuclear antigen (pcna-A)

Xenopus laevis small GTPase RhoA mRNA

Nuclear protein p30 (5G170)

Glutamate dehydrogenase 1 (glud1)

Xenopus laevis similar to PDZ and LIM domain 1 (elfin)

Ig rearranged $\mathrm{H}$ chain (26945 VH8) V-region mRNA (V-D-J-C) subgroup 8

Mus musculus chromogranin $A$

seryl-aminoacyl-tRNA synthetase 1 (sars)

Tissue inhibitor of metalloproteinases-3 (Timp3)

mitogen-activated protein kinase 8 (Mapk8)

pyruvate kinase

adenine deaminase

Fascin

microtubule-associated protein, RP/EB family, member 1 (mapre1)

g H-chain mRNA V10-region, partial cds

porin

ectonucleotide pyrophosphatase/phosphodiesterase 2 (autotaxin) (enpp2) Septin 1 (Sep1)

Xenopus tropicalis abi 1 protein (abi 1 )

Xenopus tropicalis titin immunoglobulin domain protein (myotilin) (Myot)

BTB domain protein 2 (btbd1)

Xenopus laevis non-coding RNA, associated with the germ plasm

activin receptor (XSTK2) MRNAs according to biological functional categories represented by pie chart. The cytoskeletal category is the major functional category of growth cone enriched mRNAs. C, List of known annotated genes that were at least 1.5-fold (GC/axon signal intensity ratio) enriched in Xenopus growth cones with respect to axons.

and there are some puzzling mRNAs, such as Ig rearranged $\mathrm{H}$ chain $\mathrm{V}$-region mRNA and proliferating cell nuclear antigen, that will require validation. Nonetheless, the finding that at least some mRNAs show significant enrichment in the growth cone over the axon indicates that some mRNAs are localized to subcellular compartments in growing axons.

\section{Comparison of mouse and Xenopus growth cone mRNA populations}

To investigate whether mRNAs localize to the growth cones of RGC axons in mammals and to compare with the profiles obtained in Xenopus growth cones, we conducted a similar LCM $/ \mathrm{mi}$ croarray analysis on E16 mouse retinal growth cones. Growth cones 
A

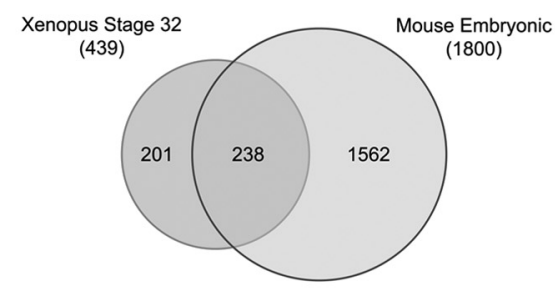

Total number of transcripts in X.laevis array $=14400$

$\%$ transcripts identified in X.laevis growth cones $=\sim 6 \%$

Total number of transcripts in mouse array $=45000$

$\%$ transcripts identified in mouse growth cones $=\sim 4.8 \%$
B Ingenuity Pathway Analysis of mRNAs present B in Xenopus and mouse growth cones: Pathways

$\begin{array}{lcc} & \text { P-value } & \text { No of molecules } \\ \text { Oxidative Phosphorylation } & 4.47 \mathrm{E}-06 & 10 \\ \text { Mitochondrial Dysfunction } & 0.001905 & 6 \\ \text { Inositol Metabolism } & 0.005129 & 2 \\ \text { ERK/MAPK Signaling } & 0.007079 & 6 \\ \text { 14-3-3-mediated Signaling } & 0.022387 & 4 \\ \text { Citrate Cycle } & 0.023442 & 2 \\ \text { Actin Cytoskeleton Signaling } & 0.044668 & 5 \\ \text { Protein Ubiquitination Pathway } & 0.047863 & 5 \\ \begin{array}{l}\text { Cell Cycle: G2/M DNA Damage } \\ \text { Checkpoint Regulation }\end{array} & 0.057544 & 2 \\ \begin{array}{l}\text { IGF-1 Signaling } \\ \text { Clathrin-mediated Endocytosis }\end{array} & 0.058884 & 4\end{array}$

C Ingenuity Pathway Analysis : Molecular, Cellular and Physiological Function

$\begin{array}{lc}\text { P-value } & \text { No of molecules } \\ 2.09 \mathrm{E}-25 & 34 \\ 2.80 \mathrm{E}-07 & 54 \\ 2.80 \mathrm{E}-07 & 43 \\ 1.89 \mathrm{E}-06 & 52 \\ 1.89 \mathrm{E}-06 & 10 \\ 1.89 \mathrm{E}-06 & 21 \\ 4.17 \mathrm{E}-06 & 14 \\ 9.88 \mathrm{E}-05 & 8 \\ 9.88 \mathrm{E}-05 & 9 \\ 1.39 \mathrm{E}-04 & 5 \\ 1.39 \mathrm{E}-04 & 5 \\ 1.39 \mathrm{E}-04 & 12 \\ 2.15 \mathrm{E}-04 & 23 \\ 1.48 \mathrm{E}-03 & 17 \\ 2.51 \mathrm{E}-03 & 18 \\ 2.51 \mathrm{E}-03 & 14 \\ 3.40 \mathrm{E}-03 & 7 \\ 3.40 \mathrm{E}-03 & 13 \\ 3.40 \mathrm{E}-03 & 5 \\ 3.57 \mathrm{E}-03 & 11\end{array}$

Figure 7. Mouse and Xenopus RGC growth cone mRNA profiles show conserved functional pathways. $\boldsymbol{A}, \mathrm{A}$ Venn diagram showing $54 \%$ overlap in the transcript profiles of 16 mouse versus stage 32 Xenopus RGC growth cone mRNA. $\boldsymbol{B}$, IPA reveals the most enriched biological pathways, such as oxidative phosphorylation $(p<0.05)$ and the number of mRNAs identified for each pathway common in both species. C, IPA identifies protein synthesis as the most enriched functional category among others common in both species $(p<0.05)$.

in E16 mouse have reached the superior colliculus (Godement et al., 1984) and are therefore comparable with Xenopus stage 32 growth cones cultured for $24 \mathrm{~h}$ in vivo. Mouse RGC axonal growth cones were laser captured after $24 \mathrm{~h}$ in culture, and the isolated RNA was amplified similar to Xenopus growth cones and hybridized to Affymetrix mouse arrays (version 1). Data analysis revealed that 2162 transcripts, representing $4.8 \%$ of the total number on the mouse arrays, were present in mouse growth cones (supplemental List S4C, available at www.jneurosci.org as supplemental material), of which 1800 had an annotated gene name. The significantly higher number of mRNAs present in mouse growth cones compared with Xenopus is likely attributable to, in part, the larger number of transcripts ( $n=$ $45,000)$ on the mouse arrays. In addition, mouse retinal neurons were cultured in serum-containing medium, whereas Xenopus retinal cultures were serum free, and, because the transport of mRNAs into axons can be increased by growth and neurotrophic factors (Zhang et al., 2001; Willis et al., 2007), transcript content could have been augmented in mouse axons. Comparative profiling showed an overlap of 238 transcripts (54\% of the total known Xenopus growth cone transcripts, $n=444$ ) between the two species, indicating a moderate degree of conservation (Fig. 7A) (supplemental List S9A, available at www.jneurosci.org as supplemental material). IPA of the pool of 238 overlapping transcripts revealed that the most common biological pathways include oxidative phosphorylation, mitochondrial dysfunction, inositol metabolism, ERK/MAPK and 14-3-3-mediated signaling, citrate cycle, and actin cytoskeleton signaling (Fig. 7B) (supplemental List $\mathrm{S} 9 B$, available at www.jneurosci.org as supplemental material). Again, mRNAs that code for protein synthesis and neurological disease proteins are among the highest functional categories with mRNAs encoding the protein synthesis machinery, in particular all the ribosomal proteins being highly represented in both species (Fig. 7C) (supplemental List S9C, available at www.jneurosci.org as supplemental material). Also, like Xenopus, ribosomal mRNAs were highly abundant, with 79 of the 80 eukaryotic ribosomal proteins of the small and large ribosomal subunits detected in mouse growth cones (Table 1) (supplemental List S4C, available at www.jneurosci.org as supplemental material). Interestingly, although Xenopus stage 32 growth cones contained only one mitochondrial ribosomal protein (mRP) namely mRPL41, several mRPs of the large ribosomal subunit (mRPL11, mRPL13, mRPL30, etc.) and one mitochondrial small ribosomal subunit (mS18C) were identified in mouse growth cones (Table 1). It is known that several mRP mRNAs are localized to the mitochondria via their $3^{\prime}$ untranslated regions (UTRs) and are associated with the cytoskeleton (Russo et al., 2008). This mRNA localization is important for rapid ribosome assembly in the mitochondria in vivo (Corral-Debrinski, 2007). Also of note is the presence of mRNAs involved in cancer, further indicating a shared role of these molecules in early developmental processes, such as neuronal migration and axon guidance, as well as in the onset of pathological conditions such as angiogenesis and cancer (Chédotal et al., 2005). These pools of mRNAs with common function across species suggest that the mRNAs identified play a physiological role in the growth cone.

\section{Growth cone mRNAs involved in axon guidance and synaptic function: Xenopus and mouse}

The growth cone plays a primary role in axon pathfinding and synaptogenesis; therefore, we next focused our analysis on mRNAs encoding molecules associated with these specific functions. A significant number of mRNAs encoding proteins important for axon guidance are, indeed, present in both Xenopus and mouse growth cones (Table 2). Interestingly, growth cones contain mRNAs for extracellular and cell-attached guidance cues, such as BMP1, semaphorins, ephrins, and Wnts, and for secreted ECM molecules, such as Laminin, and ECM-modifying metalloproteases, such as TIMP3, ADAM1a, and ADAM25. Transcripts for guidance receptors, such as Neuropilin2, Activin, and Eph receptors, and other substrate and cell adhesion molecules, such 
Table 2. Examples of mRNAs involved in axon guidance and synaptogenesis identified in either Xenopus or mouse growth cones

Cell adhesion, cell surface $\&$ receptors

L1, Neurotrimin, Catenin $\alpha 1, \beta 1$, Contactin 2, Protocadherins 9, 11, \& 14

Neuroligin1, Neuregulin 3, Sema 6C, MAGUK7, Activin receptor, EphB4a, FGF receptor

2 b, IGF- like receptor 1, Dystroglycan 1, Integrins $\alpha 3, \alpha 9, \beta 1$, Laminin receptor 1 ,

Neuropilin 2

\title{
Secreted and ECM
}

Ephrin A3, A5, B2, Netrin G1, BMP, Follistatin-like 1, Sema 3F, Sonic Hedgehog1, Wnt3, 7a, 10b, Metallotheionin A, TIMP3, ADAM1A \& 25, Neurexophilin 3, FGF1, Laminin B1 \& B2, Collagen 1A1, 5A1, 8A1, SHC1

\section{Cytoskeletal associated proteins}

\author{
Actin cytoskeleton: $\beta$-actin, Fascin, ACTR2, ARPC1a, ARPC2, RhoA, Thymosin beta 4, \\ 10, Cofilin 1, Gelsolin, Enabled homolog, Spectrin $\alpha 2$, GAP43, Profilin II, Coronin 1, \\ Kelch-like 17, Cortactin, Neurabin 1 \\ Microtubule cytoskeleton: $\alpha$-tubulin, $\beta$ - tubulin, EB1 \& 2, MAP1C3a, b, APC, Septin 1, \\ Paxillin, Stathmin 1, 2, 3 \\ Intermediate cytoskeleton: Peripherin, Vimentin \\ Motor: Kinesin 1a, 2, 5b \& c, Dynein light chain 4, 8a, heavy chain 11
}

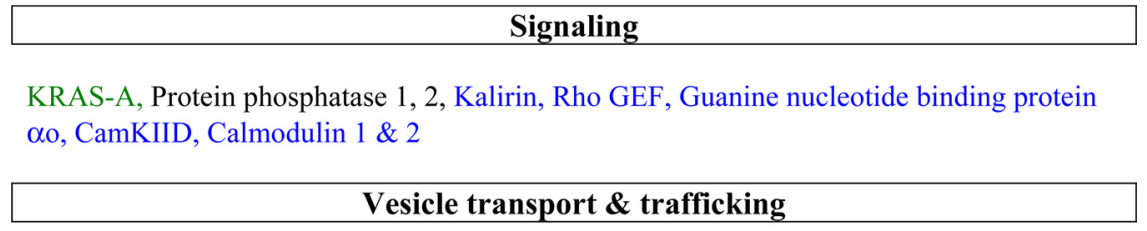

Adaptor protein complex 2, 3, Reticulon 1, 3, Cornichon homolog, clathrin light polypeptide, fasciculation and elongation protein zeta 2

Gene names are color coded based on the species and the developmental stage in which they were identified: red, Xenopus stage 32; purple, Xenopus stage 24; blue, mouse E16; green, Xenopus stage 24 and stage 32; black, Xenopus stage 32 and mouse E16; pink, Xenopus stage 24 and mouse E16; orange, Xenopus stage 24, stage 32, and mouse E16.

as integrins ( $\alpha$ and $\beta$ subunits), protocadherins, and L1, are also present. There are also mRNAs for cytoskeletal proteins, such as $\beta$-actin and $\alpha$ - and $\beta$-tubulin, and cytoskeletal regulatory proteins, such as $\beta$-Thymosin, Stathmins, Paxillin, adenomatosis polyposis coli, and Rho A (Table 2). This is consistent with previous reports showing a role for local $\beta$-actin synthesis in growth cone turning responses (Leung et al., 2006; Yao et al., 2006) and $\beta$-Thymosin synthesis for neurite outgrowth (van Kesteren et al., 2006).

The microarray data also reveal a surprising number of mRNAs associated with presynaptic function and neurotransmission, particularly in the mouse growth cones, such as synaptic vesicle components [syntaxins, Synaptosomal-associated protein 29 (SNAP29), Synaptotagamin-like 4, etc.] and synaptic cleft molecules, such as Neuroligin 1 (Table 3). Xenopus stage 32 growth cones contain several voltage-gated ion channels, as well as glutamate-like receptor and enzymes, such as glutamate dehydrogenase 1 . In addition to the voltage-gated ion channels, the mouse growth cones also harbor transcripts for adrenergic, glutamate (NMDA2D), and glycine receptors, as well as glutamate receptor-associated molecules, such as GRIP2, are also present in mouse growth cones. These findings suggest that distinct sets of mRNAs encoding functionally related proteins, such as those involved in axon guidance and synaptogenesis, are trafficked to the growth cone during the late pathfinding and/or synaptic targeting phases of guidance.

\section{Discussion}

Although previous studies have used compartmentalized chambers to isolate axons (Hengst et al., 2006; Willis et al., 2007; Taylor et al., 2009; Vogelaar et al., 2009; Andreassi et al., 2010) or fibroblast pseudopodia (Mili et al., 2008) for profiling and laser capture microdissection has been used previously to isolate specific subpopulations of neurons for profiling (Tung et al., 2008), this is the first study to apply unbiased microdissection methods for mRNA profiling of two separate extrasomal compartments. The subaxonal profiling data of developing RGCs revealed a spectrum of growth cone mRNAs. This is in line with findings in Drosophila embryos showing that $71 \%$ of the Drosophila genome is expressed in distinct subcellular patterns (Lécuyer et al., 2007) and studies in Xenopus oocytes, migrating fibroblasts, mammalian neurons and astrocytes showing hundreds of mRNAs with distinct localization patterns (Poon et al., 2006; Zhong et al., 2006; Blower et al., 2007; Matsumoto et al., 2007; Cahoy et al., 2008; Mili et al., 2008; Taylor et al., 2009). Our results also complement the recent proteomic screen of growth cone marker proteins identifying almost 1000 proteins present in growth cones (Nozumi et al., 2009).

The majority of studies on axon translation have focused on a small number of mRNAs such as cytoskeletal mRNAs identified by a candidate approach. The present study reveals that, in addition to cytoskeletal mRNAs, both Xenopus and mouse growth cones contain a large and diverse range of mRNAs. Although the 
Table 3. Key examples of mRNAs encoding synapse-associated molecules identified in either Xenopus stage 32 or mouse E16 growth cones

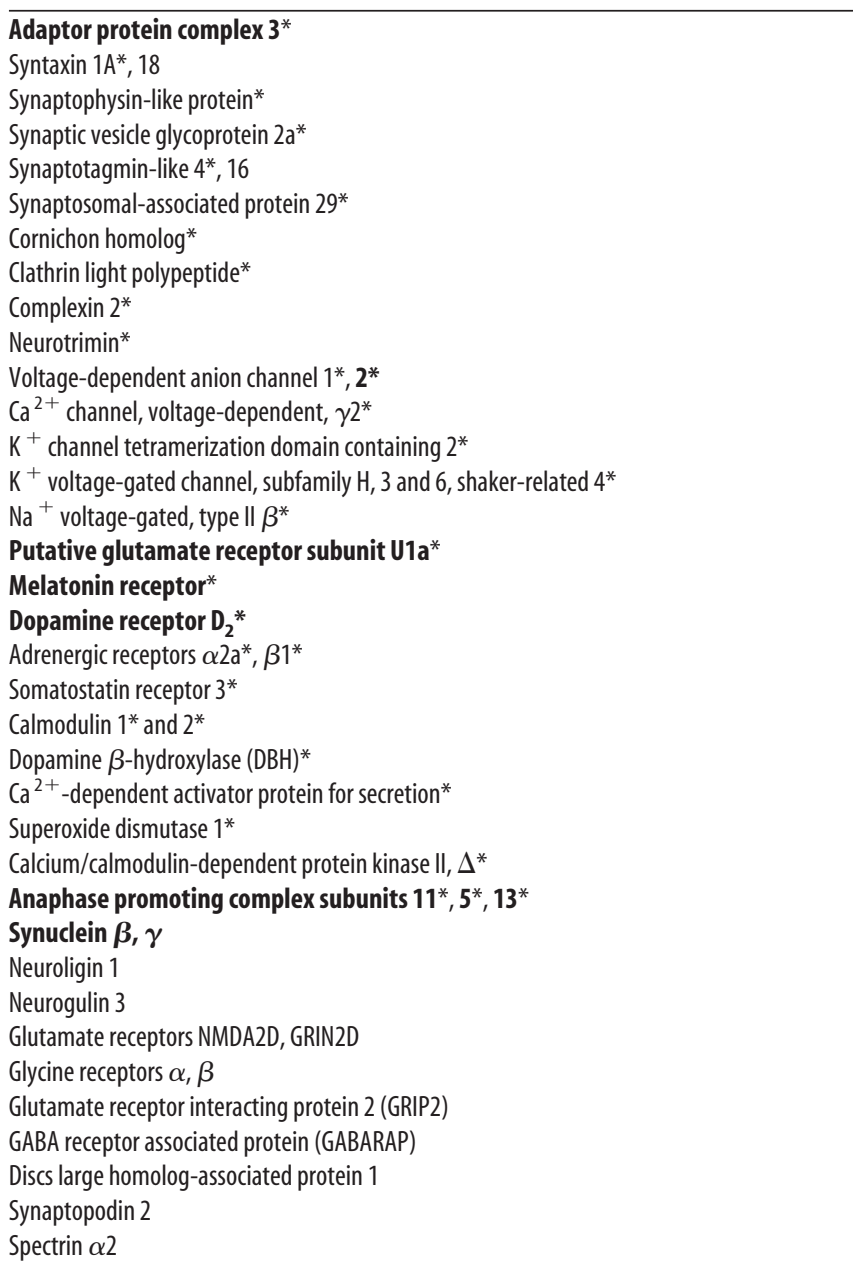

Gene names are coded based on the species and the developmental stage in which they were identified: bold font, Xenopus stage 32; roman font, mouse E16; italic font, Xenopus stage 24 and stage 32. * indicate molecules with known presynaptic function.

degree of conservation is apparently modest between the two species, it should be noted that more than half of Xenopus transcripts (54\%) are also present in mouse growth cones. The highest functional category identified in both species was that of protein synthesis. Microarray analysis similarly identified protein synthesis as one of the highest functional categories in cortical axons (Taylor et al., 2009). Indeed, mRNAs for most of the 80 eukaryotic ribosomal subunits are present in both mouse and Xenopus growth cones. This is similar to findings in mammalian cortical axons (Taylor et al., 2009), dorsal root and superior cervical ganglion axons (Andreassi et al., 2010; Gumy et al., 2010), rat hippocampal dendrites (Poon et al., 2006; Zhong et al., 2006), and Aplysia neurites (Moccia et al., 2003). Because ribosome biogenesis occurs in the nucleolus, it is puzzling to find so many ribosomal mRNAs in axons and growth cones. This peripheral localization could simply be attributable to a "spillover" of transcripts from the soma rather than specific targeting. An alternative intriguing possibility is that ribosomal mRNAs are locally synthesized in axons/growth cones to provide a local "on demand" source of nascent subunits that contribute to the maintenance and repair of soma-remote translation machinery. This possibility resonates with the finding that young growth cones, nearest the cell soma, have far fewer such mRNAs compared with old growth cones that are a long distance away. Several other protein synthesis machinery-associated molecules are also present (Table 1) (supplemental List S4, available at www. jneurosci.org as supplemental material), suggesting that growth cones may maintain or augment their protein synthetic capacity by synthesizing translation machinery locally. Such a mechanism could help to circumvent problems associated with the short halflives of some essential components when the ribosomal machinery is located at a long distance from the soma. Additional studies are needed to determine whether ribosomal proteins are made or repaired locally in the growth cone.

One of the highest functional categories identified included proteins involved in cancer, which points to similar molecular pathways underlying growth cone migration and tumor cell biology. Perhaps this is not unexpected given the common need of growth cones and tumor cells to escape local growth control and become migratory. Genetic and neurological diseases were also significant in our list, indicating that dysregulation of growth cone/axonal mRNAs may underlie developmental neurological disorders (Bear et al., 2004). Among the diverse functional mRNAs, a significant number of transcripts encode molecules involved in axon guidance in both Xenopus and mouse growth cones. These include guidance cues themselves as well as molecules involved in cue-induced signal transduction (Table 2).

Interestingly, TFs comprise a significant subset of retinal growth cone and axonal mRNAs, and this is in agreement with previous studies (Piper et al., 2008; Taylor et al., 2009). A novel role for TF mRNA was demonstrated recently by the finding that axonally synthesized cAMP response element-binding protein (CREB) is retrogradely trafficked to the soma to regulate transcription and promote neuronal survival (Cox et al., 2008). Although CREB mRNA is absent in retinal axons and growth cones, a similar mechanism involving cue-induced translation of TFs in growth cones could provide a link between the experience of the axon tip and gene-regulated cellular responses. Cell cycle molecules comprise another unexpected class of mRNAs, perhaps relating to their recently described roles in postmitotic neuronal microtubule dynamics (Frank and Tsai, 2009; Schmetsdorf et al., 2009).

As growth cones advance through the optic pathway in vivo, their experience, responsiveness, and functions change (Campbell et al., 2001; Shewan et al., 2002). At early stages, axons must advance rapidly and select the correct pathway, whereas later they must recognize their target, slow their extension, and form synapses with the correct postsynaptic cells. Thus, it might be expected that growth cones exhibit a changing complement of mRNAs to help tailor their "readiness" to changing demands. In line with this view, the old versus young growth cone profiling results showed that the number and diversity of mRNAs increases significantly over a $24 \mathrm{~h}$ period. Also prevalent at both ages are transcripts encoding proteins involved in protein synthesis and degradation, metabolism, and the cytoskeleton. Young growth cones, however, have surprisingly few receptor mRNAs, indicating that local synthesis of receptors is unlikely to play a major role in the early stages of axon pathfinding. An exception is Laminin receptor 1 . This receptor was shown previously to mediate the conversion of netrin-1-induced attraction to repulsion by laminin-1 in RGC growth cones (Höpker et al., 1999), and its known dual function as a receptor and ribosomal protein (Nelson et al., 2008) may link laminin-stimulated responses directly to translation. Although the old growth cones have an increased number of transmembrane and receptor transcripts, we 
did not find many of the classic axon guidance receptors, such as Deleted in colorectal cancer, plexins, or Roundabout, except for neuropilin 2. This suggests that developmental changes in the growth cone responses to netrin-1 and Slit are not regulated at the level of local translation of receptor mRNAs. Alternatively, mRNA localization may modulate the downstream signaling cascades of different receptor-cue interactions, because several signaling pathways are upregulated in older growth cones compared with the young ones. Likewise, mRNAs encoding cell adhesion molecules and secreted/ECM molecules are enriched in older growth cones. Of particular interest are the ephrins and their receptors, because they play roles in axon guidance and synaptogenesis (Nakagawa et al., 2000; Williams et al., 2003; Lemke and Reber, 2005; Lim et al., 2008; McClelland et al., 2009). Previous studies have shown that B-type Eph/ephrin mRNAs are present in RGC axons (Brittis et al., 2002; Mann et al., 2002), and evidence using a EphA2-green fluorescent protein reporter indicates that local synthesis of EphA in commissural spinal cord axons underlies a switch in axon responsiveness after midline crossing (Brittis et al., 2002). Our results indicate that EphB4 receptor mRNA localization is regulated posttranscriptionally because the level of EphB4 transcripts in the RGC soma is similar at both young and old ages yet they are detected exclusively in old growth cones.

A remarkable number of presynaptic protein mRNAs reside in old Xenopus and mouse growth cones but are absent in young growth cones. This suggests that a functionally related set of presynaptic mRNAs is trafficked out to the growth cone to help meet the demands of synaptogenesis, similar to mRNA splicing of a functionally coherent set of mRNAs involved in synaptic plasticity by Nova, a neuron-specific RNA-binding protein (Ule et al., 2005). Moreover, we found transcripts with known function in synaptogenesis and maturation also present in growth cones (Table 3 ).

mRNAs are trafficked selectively into axons or dendrites depending on specific sequences in their UTRs and the RNA secondary structure (Kislauskis et al., 1994; Bassell and Kelic, 2004; Andreassi et al., 2010; Vuppalanchi et al., 2010). Several of the mRNAs identified in growth cones (e.g., $\beta$-actin, Ferritin, Cyclin $\mathrm{B} 1$, ribosomal proteins) contain cis-acting sequences in their $3^{\prime}$ UTR and 5' UTR such as iron response element, cytoplasmic polyadenylation element, and TOP sequences that mediate mRNA targeting via specific RNA binding proteins such as ZBP1/ VgIRBP and iron regulatory proteins (IRP1 and IRP2) in neurons and other systems (Hentze and Kuhn, 1996; Meyuhas, 2000; Richter, 2001; Zhang et al., 2001). It is not known whether specific sequences exist to target mRNAs to the growth cone, but the finding that some mRNAs are enriched here compared with the axon is highly suggestive.

Our results support the idea that subcellular RNA localization contributes to the sensory and migratory functions of the growth cone, which comprises a functionally specialized subcompartment of the axon. Although most of the mRNAs are enriched in the axonal compartment, certain mRNAs are enriched specifically in growth cones. Similarly, the growing tips of dendrites (Crino and Eberwine, 1996) and the leading pseudopods of migrating fibroblasts (Kislauskis et al., 1994; Mili et al., 2008) show the localization of specific RNA. This suggests that an RNA localization-based mechanism might commonly underlie the plastic growth processes associated with signal-induced responses at localized subcellular sites.

\section{References}

Andreassi C, Zimmermann C, Mitter R, Fusco S, Devita S, Saiardi A, Riccio A (2010) An NGF-responsive element targets myo-inositol monophosphatase-1 mRNA to sympathetic neuron axons. Nat Neurosci [Erratum (2010) 13:1033; Devita, Serena (corrected to De Vita, Serena)] 13:291-301.

Bassell GJ, Kelic S (2004) Binding proteins for mRNA localization and local translation, and their dysfunction in genetic neurological disease. Curr Opin Neurobiol 14:574-581.

Bassell GJ, Zhang H, Byrd AL, Femino AM, Singer RH, Taneja KL, Lifshitz LM, Herman IM, Kosik KS (1998) Sorting of beta-actin mRNA and protein to neurites and growth cones in culture. J Neurosci 18:251-265.

Bear MF, Huber KM, Warren ST (2004) The mGluR theory of fragile X mental retardation. Trends Neurosci 27:370-377.

Blichenberg A, Schwanke B, Rehbein M, Garner CC, Richter D, Kindler S (1999) Identification of a cis-acting dendritic targeting element in MAP2 mRNAs. J Neurosci 19:8818-8829.

Blower MD, Feric E, Weis K, Heald R (2007) Genome-wide analysis demonstrates conserved localization of messenger RNAs to mitotic microtubules. J Cell Biol 179:1365-1373.

Bramham CR, Wells DG (2007) Dendritic mRNA: transport, translation and function. Nat Rev Neurosci 8:776-789.

Brittis PA, Lu Q, Flanagan JG (2002) Axonal protein synthesis provides a mechanism for localized regulation at an intermediate target. Cell 110:223-235.

Brumback AC, Lieber JL, Angleson JK, Betz WJ (2004) Using FM1-43 to study neuropeptide granule dynamics and exocytosis. Methods 33:287-294.

Cahoy JD, Emery B, Kaushal A, Foo LC, Zamanian JL, Christopherson KS, Xing Y, Lubischer JL, Krieg PA, Krupenko SA, Thompson WJ, Barres BA (2008) A transcriptome database for astrocytes, neurons, and oligodendrocytes: a new resource for understanding brain development and function. J Neurosci 28:264-278.

Campbell DS, Regan AG, Lopez JS, Tannahill D, Harris WA, Holt CE (2001) Semaphorin 3A elicits stage-dependent collapse, turning, and branching in Xenopus retinal growth cones. J Neurosci 21:8538-8547.

Chédotal A, Kerjan G, Moreau-Fauvarque C (2005) The brain within the tumor: new roles for axon guidance molecules in cancers. Cell Death Differ 12:1044-1056.

Cheung AW, Lam JS, Chan SO (2005) Selective inhibition of ventral temporal but not dorsal nasal neurites from mouse retinal explants during contact with chondroitin sulphate. Cell Tissue Res 321:9-19.

Cope L, Hartman SM, Göhlmann HW, Tiesman JP, Irizarry RA (2006) Analysis of Affymetrix GeneChip data using amplified RNA. Biotechniques 40:165-166, 168, 170.

Corral-Debrinski M (2007) mRNA specific subcellular localization represents a crucial step for fine-tuning of gene expression in mammalian cells. Biochim Biophys Acta 1773:473-475.

Cox LJ, Hengst U, Gurskaya NG, Lukyanov KA, Jaffrey SR (2008) Intraaxonal translation and retrograde trafficking of CREB promotes neuronal survival. Nat Cell Biol 10:149-159.

Crino PB, Eberwine J (1996) Molecular characterization of the dendritic growth cone: regulated mRNA transport and local protein synthesis. Neuron 17:1173-1187.

Dingwell KS, Holt CE, Harris WA (2000) The multiple decisions made by growth cones of RGCs as they navigate from the retina to the tectum in Xenopus embryos. J Neurobiol 44:246-259.

Drescher U, Bonhoeffer F, Müller BK (1997) The Eph family in retinal axon guidance. Curr Opin Neurobiol 7:75-80.

Flanagan JG (2006) Neural map specification by gradients. Curr Opin Neurobiol 16:59-66.

Flanagan JG, Vanderhaeghen P (1998) The ephrins and Eph receptors in neural development. Annu Rev Neurosci 21:309-345.

Frank CL, Tsai LH (2009) Alternative functions of core cell cycle regulators in neuronal migration, neuronal maturation, and synaptic plasticity. Neuron 62:312-326.

Godement P, Salaün J, Imbert M (1984) Prenatal and postnatal development of retinogeniculate and retinocollicular projections in the mouse. J Comp Neurol 230:552-575.

Goode BL, Drubin DG, Barnes G (2000) Functional cooperation between the microtubule and actin cytoskeletons. Curr Opin Cell Biol 12:63-71.

Gumy LF, Yeo GS, Tung YC, Zivraj KH, Willis D, Coppola G, Lam BY, Twiss 
JL, Holt CE, Fawcett JW (2010) Transcriptome analysis of embryonic and adult sensory axons reveals changes in mRNA repertoire localisation. RNA, in press.

Hengst U, Cox LJ, Macosko EZ, Jaffrey SR (2006) Functional and selective RNA interference in developing axons and growth cones. J Neurosci 26:5727-5732.

Hentze MW, Kühn LC (1996) Molecular control of vertebrate iron metabolism: mRNA-based regulatory circuits operated by iron, nitric oxide, and oxidative stress. Proc Natl Acad Sci U S A 93:8175-8182.

Hindges R, McLaughlin T, Genoud N, Henkemeyer M, O’Leary DD (2002) EphB forward signaling controls directional branch extension and arborization required for dorsal-ventral retinotopic mapping. Neuron 35:475-487.

Holt CE (1984) Does timing of axon outgrowth influence initial retinotectal topography in Xenopus? J Neurosci 4:1130-1152.

Höpker VH, Shewan D, Tessier-Lavigne M, Poo M, Holt C (1999) Growthcone attraction to netrin- 1 is converted to repulsion by laminin-1. Nature 401:69-73.

Job C, Eberwine J (2001) Localization and translation of mRNA in dendrites and axons. Nat Rev Neurosci 2:889-898.

Kiebler MA, Bassell GJ (2006) Neuronal RNA granules: movers and makers. Neuron 51:685-690.

Kislauskis EH, Zhu X, Singer RH (1994) Sequences responsible for intracellular localization of beta-actin messenger RNA also affect cell phenotype. J Cell Biol 127:441-451.

Koenig E, Giuditta A (1999) Protein-synthesizing machinery in the axon compartment. Neuroscience 89:5-15.

Lai KO, Ip NY (2009) Synapse development and plasticity: roles of ephrin/ Eph receptor signaling. Curr Opin Neurobiol 19:275-283.

Lécuyer E, Yoshida H, Parthasarathy N, Alm C, Babak T, Cerovina T, Hughes TR, Tomancak P, Krause HM (2007) Global analysis of mRNA localization reveals a prominent role in organizing cellular architecture and function. Cell 131:174-187.

Lemke G, Reber M (2005) Retinotectal mapping: new insights from molecular genetics. Annu Rev Cell Dev Biol 21:551-580.

Leung KM, van Horck FP, Lin AC, Allison R, Standart N, Holt CE (2006) Asymmetrical beta-actin mRNA translation in growth cones mediates attractive turning to netrin-1. Nat Neurosci 9:1247-1256.

Lim BK, Matsuda N, Poo MM (2008) Ephrin-B reverse signaling promotes structural and functional synaptic maturation in vivo. Nat Neurosci 11:160-169.

Lin AC, Holt CE (2008) Function and regulation of local axonal translation. Curr Opin Neurobiol 18:60-68.

Lin AC, Tan CL, Lin CL, Strochlic L, Huang YS, Richter JD, Holt CE (2009) Cytoplasmic polyadenylation and cytoplasmic polyadenylation elementdependent mRNA regulation are involved in Xenopus retinal axon development. Neural Dev 4:8.

Mann F, Ray S, Harris W, Holt C (2002) Topographic mapping in dorsoventral axis of the Xenopus retinotectal system depends on signaling through ephrin-B ligands. Neuron 35:461-473.

Mann F, Miranda E, Weinl C, Harmer E, Holt CE (2003) B-type Eph receptors and ephrins induce growth cone collapse through distinct intracellular pathways. J Neurobiol 57:323-336.

Martin KC, Ephrussi A (2009) mRNA localization: gene expression in the spatial dimension. Cell 136:719-730.

Matsumoto M, Setou M, Inokuchi K (2007) Transcriptome analysis reveals the population of dendritic RNAs and their redistribution by neural activity. Neurosci Res 57:411-423.

McClelland AC, Sheffler-Collins SI, Kayser MS, Dalva MB (2009) Ephrin-B1 and ephrin-B2 mediate EphB-dependent presynaptic development via syntenin-1. Proc Natl Acad Sci U S A 106:20487-20492.

Meyuhas O (2000) Synthesis of the translational apparatus is regulated at the translational level. Eur J Biochem 267:6321-6330.

Mili S, Moissoglu K, Macara IG (2008) Genome-wide screen reveals APCassociated RNAs enriched in cell protrusions. Nature 453:115-119.

Ming GL, Wong ST, Henley J, Yuan XB, Song HJ, Spitzer NC, Poo MM (2002) Adaptation in the chemotactic guidance of nerve growth cones. Nature 417:411-418.

Moccia R, Chen D, Lyles V, Kapuya E, E Y, Kalachikov S, Spahn CM, Frank J, Kandel ER, Barad M, Martin KC (2003) An unbiased cDNA library prepared from isolated Aplysia sensory neuron processes is enriched for cytoskeletal and translational mRNAs. J Neurosci 23:9409-9417.
Nakagawa S, Brennan C, Johnson KG, Shewan D, Harris WA, Holt CE (2000) Ephrin-B regulates the Ipsilateral routing of retinal axons at the optic chiasm. Neuron 25:599-610.

Nelson J, McFerran NV, Pivato G, Chambers E, Doherty C, Steele D, Timson DJ (2008) The $67 \mathrm{kDa}$ laminin receptor: structure, function and role in disease. Biosci Rep 28:33-48.

Nieuwkoop PD, Faber J (1967) Normal table of Xenopus laevis (Daudin). Ed 2. Amsterdam: North Holland.

Nozumi M, Togano T, Takahashi-Niki K, Lu J, Honda A, Taoka M, Shinkawa T, Koga H, Takeuchi K, Isobe T, Igarashi M (2009) Identification of functional marker proteins in the mammalian growth cone. Proc Natl Acad Sci U S A 106:17211-17216.

Patel OV, Suchyta SP, Sipkovsky SS, Yao J, Ireland JJ, Coussens PM, Smith GW (2005) Validation and application of a high fidelity mRNA linear amplification procedure for profiling gene expression. Vet Immunol Immunopathol 105:331-342.

Phillips J, Eberwine JH (1996) Antisense RNA amplification: a linear amplification method for analyzing the mRNA population from single living cells. Methods 10:283-288.

Piper M, Salih S, Weinl C, Holt CE, Harris WA (2005) Endocytosisdependent desensitization and protein synthesis-dependent resensitization in retinal growth cone adaptation. Nat Neurosci 8:179-186.

Piper M, Anderson R, Dwivedy A, Weinl C, van Horck F, Leung KM, Cogill E, Holt C (2006) Signaling mechanisms underlying Slit2-induced collapse of Xenopus retinal growth cones. Neuron 49:215-228.

Piper M, Dwivedy A, Leung L, Bradley RS, Holt CE (2008) NFprotocadherin and TAF1 regulate retinal axon initiation and elongation in vivo. J Neurosci 28:100-105.

Poon MM, Choi SH, Jamieson CA, Geschwind DH, Martin KC (2006) Identification of process-localized mRNAs from cultured rodent hippocampal neurons. J Neurosci 26:13390-13399.

Richter JD (2001) Think globally, translate locally: what mitotic spindles and neuronal synapses have in common. Proc Natl Acad Sci U S A 98:7069-7071.

Russo A, Cirulli C, Amoresano A, Pucci P, Pietropaolo C, Russo G (2008) cis-acting sequences and trans-acting factors in the localization of mRNA for mitochondrial ribosomal proteins. Biochim Biophys Acta 1779:820-829.

Schmetsdorf S, Arnold E, Holzer M, Arendt T, Gärtner U (2009) A putative role for cell cycle-related proteins in microtubule-based neuroplasticity. Eur J Neurosci 29:1096-1107.

Shewan D, Dwivedy A, Anderson R, Holt CE (2002) Age-related changes underlie switch in netrin-1 responsiveness as growth cones advance along visual pathway. Nat Neurosci 5:955-962.

Shirasaki R, Mirzayan C, Tessier-Lavigne M, Murakami F (1996) Guidance of circumferentially growing axons by netrin-dependent and -independent floor plate chemotropism in the vertebrate brain. Neuron 17:1079-1088.

Stein E, Zou Y, Poo M, Tessier-Lavigne M (2001) Binding of DCC by netrin-1 to mediate axon guidance independent of adenosine A2B receptor activation. Science 291:1976-1982.

Taylor AM, Berchtold NC, Perreau VM, Tu CH, Li Jeon N, Cotman CW (2009) Axonal mRNA in uninjured and regenerating cortical mammalian axons. J Neurosci 29:4697-4707.

Tung YC, Ma M, Piper S, Coll A, O’Rahilly S, Yeo GS (2008) Novel leptinregulated genes revealed by transcriptional profiling of the hypothalamic paraventricular nucleus. J Neurosci 28:12419-12426.

Ule J, Ule A, Spencer J, Williams A, Hu JS, Cline M, Wang H, Clark T, Fraser C, Ruggiu M, Zeeberg BR, Kane D, Weinstein JN, Blume J, Darnell RB (2005) Nova regulates brain-specific splicing to shape the synapse. Nat Genet 37:844-852.

van Kesteren RE, Carter C, Dissel HM, van Minnen J, Gouwenberg Y, Syed NI, Spencer GE, Smit AB (2006) Local synthesis of actin-binding protein $\beta$-thymosin regulates neurite outgrowth. J Neurosci 26:152-157.

Vogelaar CF, Gervasi NM, Gumy LF, Story DJ, Raha-Chowdhury R, Leung KM, Holt CE, Fawcett JW (2009) Axonal mRNAs: characterisation and role in the growth and regeneration of dorsal root ganglion axons and growth cones. Mol Cell Neurosci 42:102-115.

Vuppalanchi D, Coleman J, Yoo S, Merianda TT, Yadhati AG, Hossain J, Blesch A, Willis DE, Twiss JL (2010) Conserved 3'UTR sequences direct subcellular localization of chaperone protein mRNAs in neurons. J Biol Chem 285:18025-18038. 
Williams SE, Mann F, Erskine L, Sakurai T, Wei S, Rossi DJ, Gale NW, Holt CE, Mason CA, Henkemeyer M (2003) Ephrin-B2 and EphB1 mediate retinal axon divergence at the optic chiasm. Neuron 39:919-935.

Willis DE, van Niekerk EA, Sasaki Y, Mesngon M, Merianda TT, Williams GG, Kendall M, Smith DS, Bassell GJ, Twiss JL (2007) Extracellular stimuli specifically regulate localized levels of individual neuronal mRNAs. J Cell Biol 178:965-980.

Willis D, Li KW, Zheng JQ, Chang JH, Smit A, Kelly T, Merianda TT, Sylvester J, van Minnen J, Twiss JL (2005) Differential transport and local translation of cytoskeletal, injury-response, and neurodegeneration protein mRNAs in axons. J Neurosci 25:778-791.

Wu KY, Hengst U, Cox LJ, Macosko EZ, Jeromin A, Urquhart ER, Jaffrey SR (2005) Local translation of RhoA regulates growth cone collapse. Nature 436:1020-1024

Wu Z, Irizarry RA, Gentleman R, Murillo FM, Spencer F (2004) A model based background adjustment for oligonucleotide expression arrays. Working papers, Department of Biostatistics, Johns Hopkins University.

Yao J, Sasaki Y, Wen Z, Bassell GJ, Zheng JQ (2006) An essential role for beta-actin mRNA localization and translation in $\mathrm{Ca}^{2+}$-dependent growth cone guidance. Nat Neurosci 9:1265-1273.

Zhang HL, Eom T, Oleynikov Y, Shenoy SM, Liebelt DA, Dictenberg JB, Singer RH, Bassell GJ (2001) Neurotrophin-induced transport of a betaactin mRNP complex increases beta-actin levels and stimulates growth cone motility. Neuron 31:261-275.

Zhang K, Hu S, Wu J, Chen L, Lu J, Wang X, Liu X, Zhou B, Yen Y (2009) Overexpression of RRM2 decreases thrombspondin-1 and increases VEGF production in human cancer cells in vitro and in vivo: implication of RRM2 in angiogenesis. Mol Cancer 8:11.

Zhong J, Zhang T, Bloch LM (2006) Dendritic mRNAs encode diversified functionalities in hippocampal pyramidal neurons. BMC Neurosci 7:17. 